Check for updates

Cite this: RSC Adv., 2019, 9, 20118

Received 17th April 2019 Accepted 8th June 2019

DOI: 10.1039/c9ra02907a

rsc.li/rsc-advances

\title{
Coated silver nanoparticles: synthesis, cytotoxicity, and optical properties
}

Heba Mohamed Fahmy, ${ }^{\text {a }}$ Ayaat Mahmoud Mosleh, ${ }^{a}$ Aya Abd Elghany, ${ }^{b}$ Engy Shams-

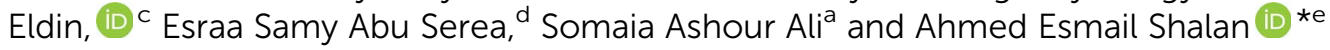

Coated silver nanoparticles (AgNPs) have recently become a topic of interest due to the fact that they have several applications such as in electronic, antimicrobial, industrial, optical, and medical fields as biosensors and drug delivery systems. However, the use of AgNPs in medical fields remains somewhat limited due to their probable cytotoxic effect. Researchers have succeeded in reducing the toxicity of silver particles by coating them with different substances. Generally, the coating of AgNPs leads to change in their properties depending on the type of the coating material as well as the layer thickness. This review covers the state-of-the-art technologies behind (a) the synthesis of coated AgNPs including coating methods and coating materials, (b) the cytotoxicity of coated AgNPs and (c) the optical properties of coated AgNPs.

\section{Introduction}

Nanotechnology is related to the different disciplines of science and also has applications in various aspects of daily life such as the diagnosis and treatment of diseases. ${ }^{1}$ Nanomaterials are more reactive and effective compared to bulk

aBiophysics Department, Faculty of Science, Cairo University, 12613, Egypt. E-mail: hfahmy@sci.cu.edu.eg

${ }^{b}$ Biochemistry Department, Faculty of Science, Cairo University, 12613, Egypt ${ }^{c}$ Food Technology Research Institute, Agriculture Research Center, Giza, Egypt ${ }^{d}$ Chemistry \& Biochemistry Department, Faculty of Science, Cairo University, 12613, Egypt

${ }^{e}$ Central Metallurgical Research and Development Institute, P. O. Box 87, Helwan, 11422, Cairo, Egypt. E-mail: a.shalan133@gmail.com; Fax: +202-25010639; Tel: $+202-25010640-43$

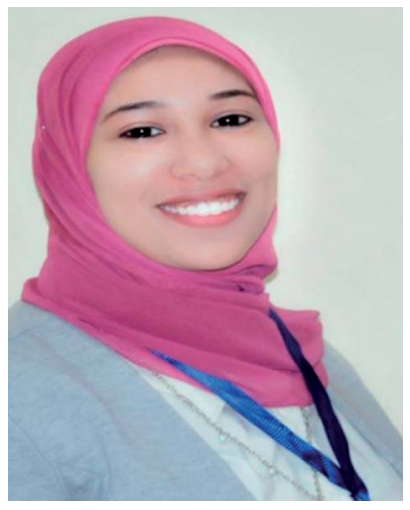

She is a demonstrator and a Master student at the Biophysics Department, Faculty of Sciences, Cairo University. She graduated in biophysics (2017) with an excellent grade. She has two graduation projects related to the natural fluorescence spectroscopy of human blood plasma in the diagnosis of cancer as well as the comparison between different pairwise protein alignment sequence programs on the web. Her interests are the synthesis of metal nanoparticles and biophysics applications. materials because of the larger surface area related to volume. They also present a potential in surface chemistry as compared to different materials because they can be loaded with functional groups that can target the molecules of interest. In addition, the physical characteristics of nanosubstances (e.g., morphology, size, chemical composition and porosity) can directly affect the performance of the materials. ${ }^{2,3}$ The features of nanoparticles are obtained through their size and optical measurements, ${ }^{4}$ colloidal stability in water, ${ }^{5}$ ability to enter living tissues ${ }^{6}$ and antibacterial efficiency. ${ }^{7}$

Nanosilver ranging in size between 1 and 100 nanometers plays a major role in nanotechnology and is used widely now in many applications. As an example, in nanomedicine, the small particles have the ability to enter the cells; hence, there is an

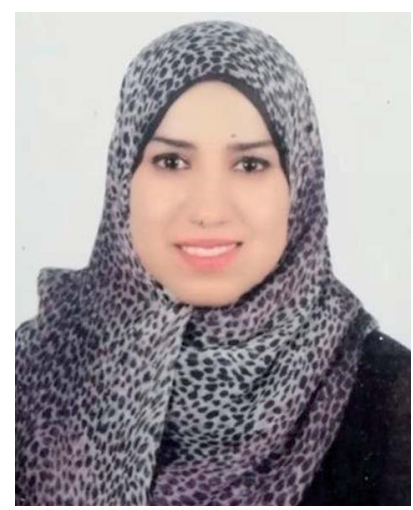

She is a Master student at the Biochemistry Department, Faculty of Science, Cairo University. She is working as a research assistant for a project of nanotechnology in the Biochemistry and Molecular biology department at the Theodor Bilharz Research Institute, Egypt. Her interests are related to nanoscience and molecular biology applications. 
interaction between the nanoparticles and the compartments of the cells. There are many factors that determine the potential action and cytotoxicity of nanosilver; these include the particle size, exposure dose, coating materials, aggregation of nanoparticles and the organism or the type of cells to be tested. $^{8}$

Core-shell nanoparticles are types of nanoparticles having great features and many applications in biology and sensing. Many of these core-shell nanostructures are produced with extensive features; they can be applied in catalytic reactions and in solving the energy problems by adjusting their cores and shells. ${ }^{9}$

Subsequently, nanoparticles, especially silver nanoparticles (AgNPs), can react with many microorganisms (e.g., fungi, bacteria and viruses); thus, they may act like antibacterial as well as anti-parasitic agents. In addition, AgNPs have been proven to be perfect carriers in drug delivery. Due to their wide use in biological applications, the study of the cytotoxicity of AgNPs becomes evident. ${ }^{1}$ AgNPs have various

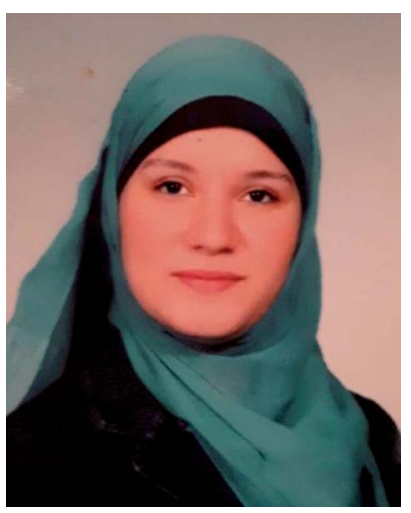

She is currently a PhD student at the Food Technology Research Institute, Agriculture Research Center. In addition, she has studied Science at the Cairo University (2005). She was awarded with Master scholarship from the Academy of Scientific Research and Technology (ASRT, 2010) and obtained her Master degree in Biochemistry from the Cairo University (2013). Furthermore, she has attended many courses related to scientific research. Her interests are chemical synthesis and biochemistry applications.

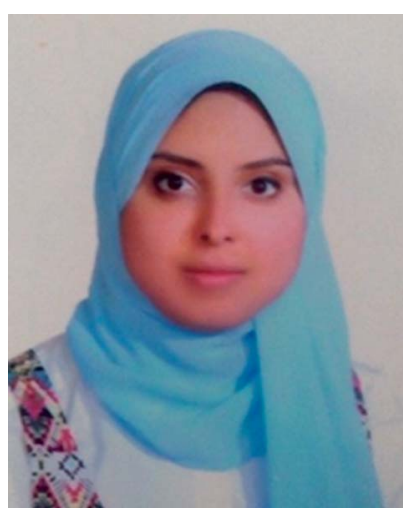

She graduated from the Faculty of Science, Cairo University, Egypt (2018) in Chemistry and Biochemistry. Furthermore, she joined the Biophysics Scientific Society association (CUBSS) at the Cairo University as an assistant researcher since 2016. She has published two book chapters, some articles and a review article related to chemistry and materials science. Her interests are synthesis and characterization of nanomaterials, photocatalysis and materials science applications. applications in medicine, engineering, and pharmacology. ${ }^{10}$ They have high efficiency to kill bacteria either in solutions or components; also, AgNPs are widely used in textile and food industries. ${ }^{11}$

Coating is an excellent technique to enhance the advantages of any nanoparticle materials. This coating technique can increase the stability of AgNPs through the electrosteric stabilization among particles and can decrease their agglomeration. One of the most important roles of coating is to prevent the cytotoxic effect of AgNPs against living cells. The function of a coating is highly dependent on the features of the coating substances such as organic coating substances (polysaccharides, proteins, polymer, etc.) and inorganic coating substances (chloride, sulfides, etc). Many tested coating substances have been proven to be effective in stabilizing AgNPs, maintaining their specific shape and minimizing silver ions, which are important factors that contribute to the toxicity of AgNPs. ${ }^{12}$

The special properties of coated AgNPs lead to many applications in different fields; for example, AgNPs coated with the capping agent poly vinyl pyrrolidone (PVP) can cause angiogenesis via the production of an angiogenic factor. ${ }^{13}$ Chitosan-coated triangular silver nanoparticles can act as photothermal agents against human non-small lung cancer cells due to the high performance of strong resonances in a near-infrared light. ${ }^{14}$ A suture coated with AgNPs has high anti-inflammatory efficacy in intestinal anastomosis at the beginning of healing in mice. ${ }^{5}$ PVP-coated silver nanoparticles of various sizes have an anti-leukemia effect against multiple human acute myeloid leukemia. ${ }^{15}$ Furthermore, a low-density polyethylene polymer matrix, including $\mathrm{Ag}$ and ZnO nanoparticles, can extend and preserve the shelf life of orange juice at $4{ }^{\circ} \mathrm{C}^{16,17}$ In the models of animals, there is improvement in injured tissues due to new collagen synthesis, inflammatory cell infiltration, congestion, and fibroblast proliferation. Therefore, AgNPs modified with

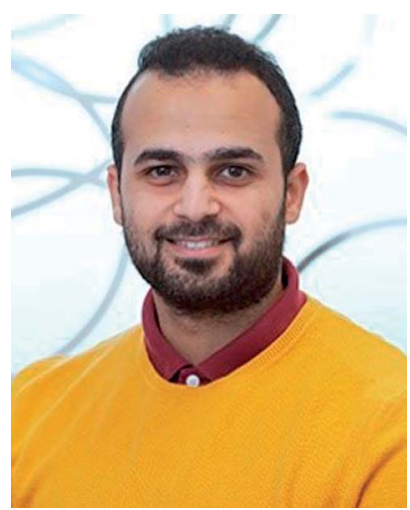

He is currently a postdoctoral researcher at BCMaterials, UPV/ EHU, Spain. He obtained his BSc (2008) and MSc (2012) in Materials Science from the Ain Shams University and the Central Metallurgical $R \& D$ Institute, Egypt, respectively. He obtained his $P h D$ (2017) from the Hokkaido University, Japan, with Prof. Hiroaki Misawa in collaboration with Prof. Eric Diau - NCTU - Taiwan. He obtained a DAAD fellowship in (i-MEET-FAU), Germany with Prof. Christoph Brabec (2013) and CIN2, UAB, Spain with Prof. Monica Cantu (2011). His work has been summarized in $>30$ articles (with h index of 16), which reflects his interest in physical chemistry, nanotechnology and materials science. 
oligonucleotides improve wound healing without any side effects. ${ }^{18}$ Environmental protection, medical diagnostics, and food control are the examples of biosensing applications that employ poly vinyl pyrrolidone-coated silver nanoparticles as color indicators. ${ }^{\mathbf{1 9}}$

To confirm the benefits of the coating process, previous studies can prove via Fourier transform infrared spectroscopy (FTIR) that the group of amides found in the proteins of some plant extracts has the ability to adhere on the metal surface. This phenomenon can lead to the protection of the surface of AgNPs from oxidation (capping of AgNPs) and prevent the agglomeration process. ${ }^{20,21}$ Chemical surface science shows the correlation between the AgNP toxicity to living cells and their outer surface properties. The idea of coating these materials was directed towards improving the properties of the surface in terms of reducing toxicity and increasing stability through methods such as thiolation and encapsulation by silica. ${ }^{22,23}$ Different coating methods and coating substances of AgNPs have been summarized in Fig. 1.

\section{Synthesis of coated silver nanoparticles (AgNPs)}

\subsection{Coating methods}

2.1.1 Polymerization method. There are different ways of polymer and nanosilver composite incorporation, where nanosilver is dispersed on the surface of a polymer: (1) first, a polymer is fabricated with nanosilver, followed by attaching it to the surface; (2) a polymer solidification process occurs on the surface of the targeted object and then, it is incorporated with nanosilver particles; (3) the monomer is attached to the nanoparticle (NP) surface, followed by in situ polymerization. In all cases, the most important step is the attachment of the polymer on the surface of the object.

Herein, we will concentrate on the fabrication pathways of coating polymer-nanosilver composites via attachment methods. ${ }^{15}$

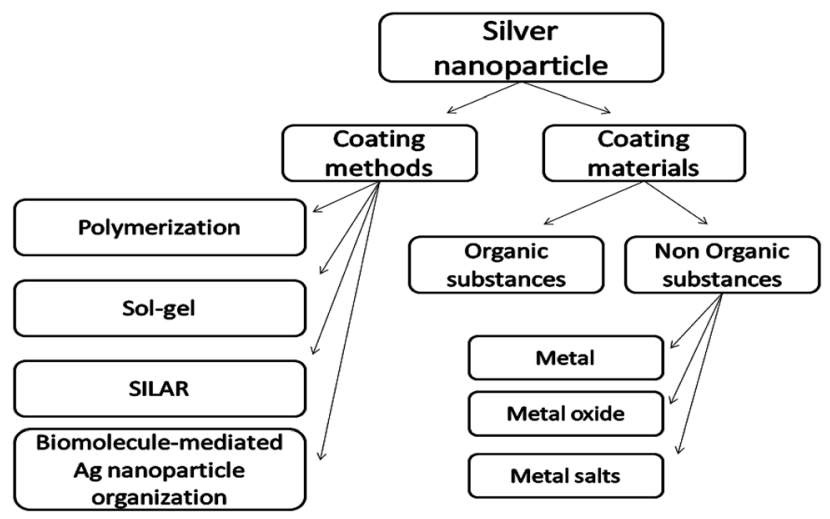

Fig. 1 Schematic representation of different coating methods and coating substances of AgNPs. "SILAR: Successive Ionic Layer Adsorption and Reaction".
Incorporation of nanosilver. There are several developed methods for the insertion of nanosilver into the polymer matrix. Nanosilver incorporation is primarily performed via direct adsorption or in situ synthesis. The first approach, i.e., direct adsorption of nanosilver is very controllable and simple; however, AgNPs can easily aggregate during this method. For example, in a previous work of Dacarro et al., AgNPs were adsorbed directly on a PEI layer and were attached covalently. ${ }^{24}$ In that work, to prepare an AgNP complex in the PEI monolayer, AgNPs capped with citrate (colloidal suspension) were immersed in SURFACE-PEI glasses at room temperature for different time intervals (15 minutes-18 hours). ${ }^{25}$ Afterwards, they were sonicated (obtained glasses) in water for 5 minutes. By increasing the time of adsorption, the color changed (yellow, red, brown, and black, sequentially), where black color indicated the successful attachment of nanocomposites but with aggregation. This process was repeated 2 times and then, the glasses were blow-dried with a nitrogen stream and kept in the dark, as illustrated in Scheme $1 .^{24}$

For further study of $\mathrm{Ag}$ nanoparticles, AFM images were obtained: the surfaces show very low roughness with a homogeneous structure. Fig. 2a displaying SURF-PEI-NPmodified glass slides prepared at 15 min shows that almost 282 NPs can be counted, leading to a lower amount of grafted AgNPs. The AFM imaging of dipped slides for a longer time (18 h) exhibited a larger NP diameter (Fig. 2b). The red shift and the larger size were obviously related to the change in the outer shape of NPs, as shown via absorbance spectra (Fig. 2c and $\mathrm{d}$ ).

The results indicated that the glasses loaded with $\operatorname{Ag}(\mathrm{I})$ did not show any significant changes in the contact angle when compared to those modified with SURF-PEI. Also, $42 \pm 3$ average static water contact angle for samples containing silver ions was recorded. ${ }^{26}$ The height of NPs was $6.0 \pm 1.6 \mathrm{~nm}$ with a diameter of $7 \pm 4 \mathrm{~nm}$, as calculated by TEM. ${ }^{25}$ To illuminate
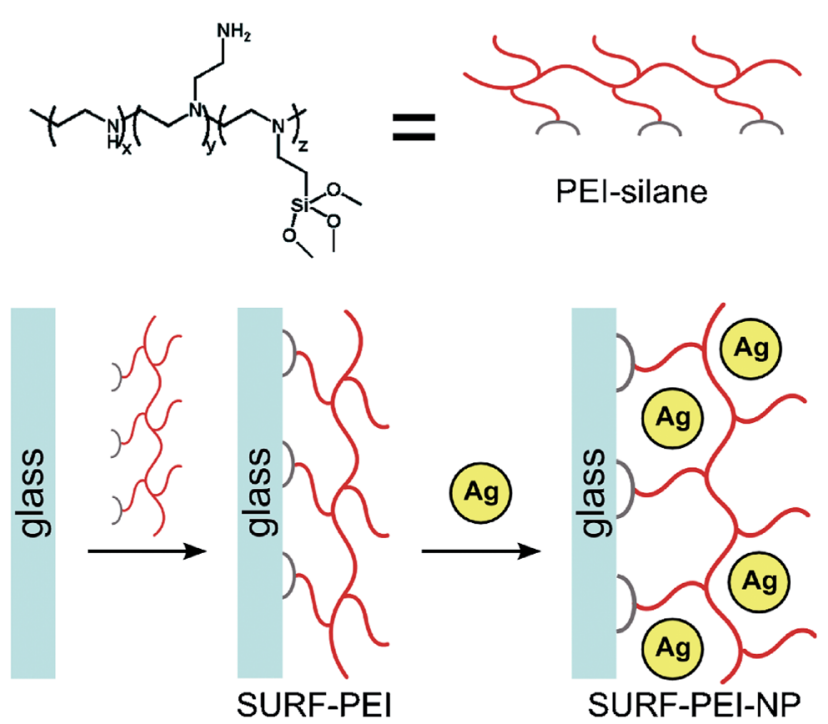

Scheme 1 Schematic representation of PEl-silane structure and twostep synthesis of a AgNP monolayer grafted on PEI SAM ${ }^{24}$ (adapted with permission from Royal Society of Chemistry, 2011). 

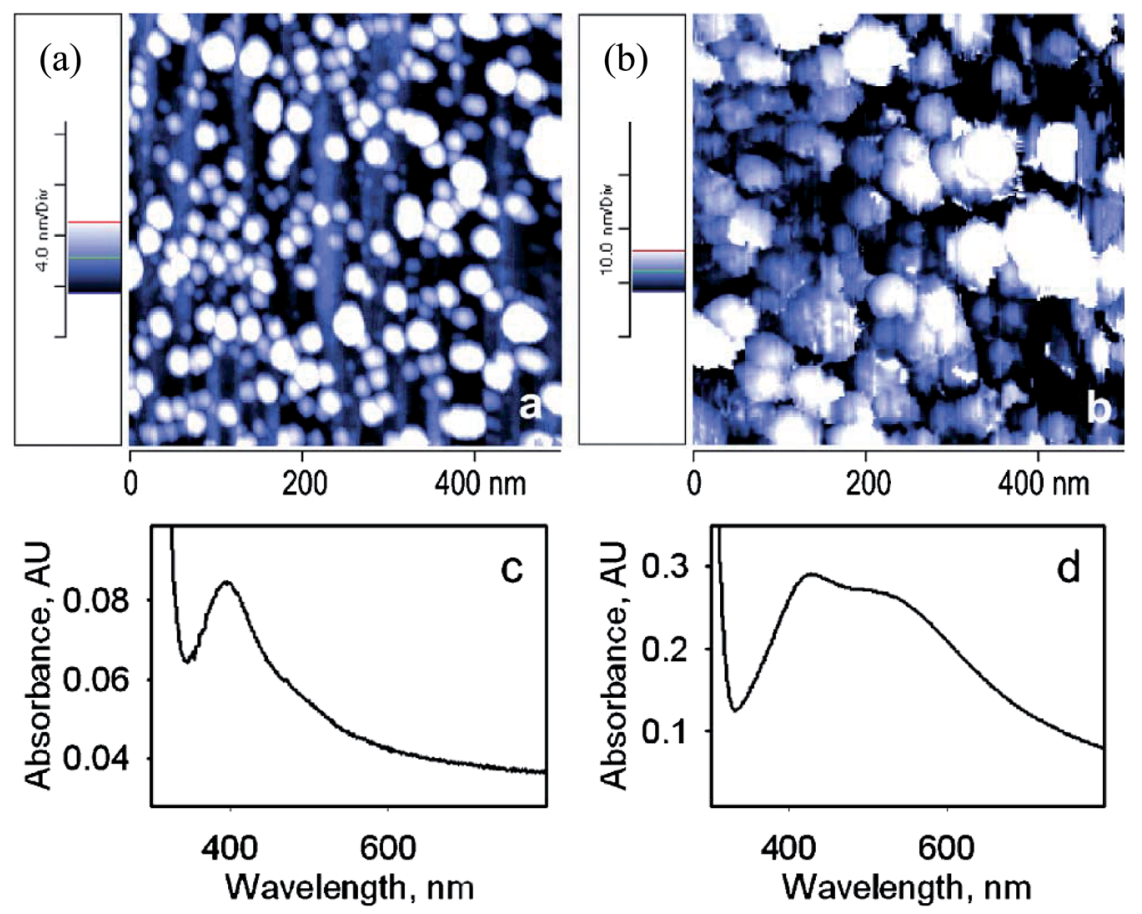

Fig. 2 (a and b) AFM topography images $(500 \times 500 \mathrm{~nm}$ ) of SURF-PEI-NP-modified glass slides prepared at $15 \mathrm{~min}$ (a) and $18 \mathrm{~h}$ (b) dipping times. (c and d) UV-Vis spectra of the same slides ((c) $15 \mathrm{~min}$, (d) $18 \mathrm{~h}$ dipping time) ${ }^{24}$ (adapted with permission from Royal Society of Chemistry, 2011).

the higher quantity of Ag, which was found by an ICP-OES test, it was assumed that the branched structure of PEI induced the formation of multilayer nanoparticles instead of monolayer ones. $^{24}$

The second approach, namely, "in situ synthesis" is comparatively harder to be achieved because of the silver ion loading. It is more beneficial when compared to direct attachment adsorption due to the formation of homogeneously distributed AgNPs in the matrixes. ${ }^{27}$ Silver nanoparticles were loaded by the in situ synthesis method. Via ion interchange, $\mathrm{Ag}$ ions were immobilized using an $\mathrm{AgNO}_{3}$ solution. Silver ions $\left(\mathrm{Ag}^{+}\right)$linked electrostatic pairs with the carboxylate groups of PAA during the immersion step. The loading step took 5 minutes. Then, silver was reduced by a dimethylamineborane solution (reducing agent) to generate Ag particles. The samples were washed in ultrapure water between each loading and reduction step. This cycle could be repeated as required to stimulate the growth of AgNPs. ${ }^{28}$

This matrix demonstrates the benefits of inorganic materials, such as chemical stability and mechanical strength, in addition to the porosity, which permit ion exchange with the surrounding medium. ${ }^{29}$

A dramatic color change was shown by the thin films when they were immersed in the DMAB solution. Then, the samples turned golden-yellowish instantly. Such a change in the visible absorption spectrum of the samples was due to the SPR phenomenon..$^{\mathbf{3 0}, 31}$ The UV-Vis spectrum indicated the presence of silver nanoparticles produced inside the coating. Moreover, elemental analysis using the EDX technique confirmed the presence of silver inside the hybrid coatings (Fig. 3a and b). ${ }^{29}$

The intensity of an absorption band is used as the indicator of the amount of AgNP formed. When the samples are subjected to numerous cycles, the quantity and the size of nanoparticles increase. ${ }^{28}$ There is a direct relationship between the cycles number and the amount of trapped AgNPs inside the thin film, as shown in Fig. 3a. ${ }^{29}$

Surface attachment via physical adsorption. In this phenomenon, the modification of a surface using polymers and nanosilver composite coatings is simultaneous. Usually in physical adsorption, the van der Waals forces are the main forces that are responsible for the adsorption of species on the surface of an adsorbent. Furthermore, other different forces can be used to induce physical adsorption such as hydrogen bonding and electrostatic forces due to dipolar attraction. Since the forces that keep molecules in the liquid phase are of electrostatic or van der Waals type, when a solid surface at a temperature $T$ is in contact with vapor, whose critical temperature $T_{\mathrm{c}}$ is higher than $T$, the system undergoes multilayer adsorption. This phenomenon is manifested with the formation of a relatively thick film, whose thickness depends on the relative pressure of the vapor but is usually in the 3-15 $\AA$ interval (the relative pressure $x$ is defined as the ratio of the partial pressure $p$ to saturated vapor pressure $p_{0}$ at the considered temperature). This approach is simple and inexpensive and it can be used to connect different functional polymers containing nanoparticles on adjacent chemical groups or charges. ${ }^{32}$ Moreover, most of the surface attachment 


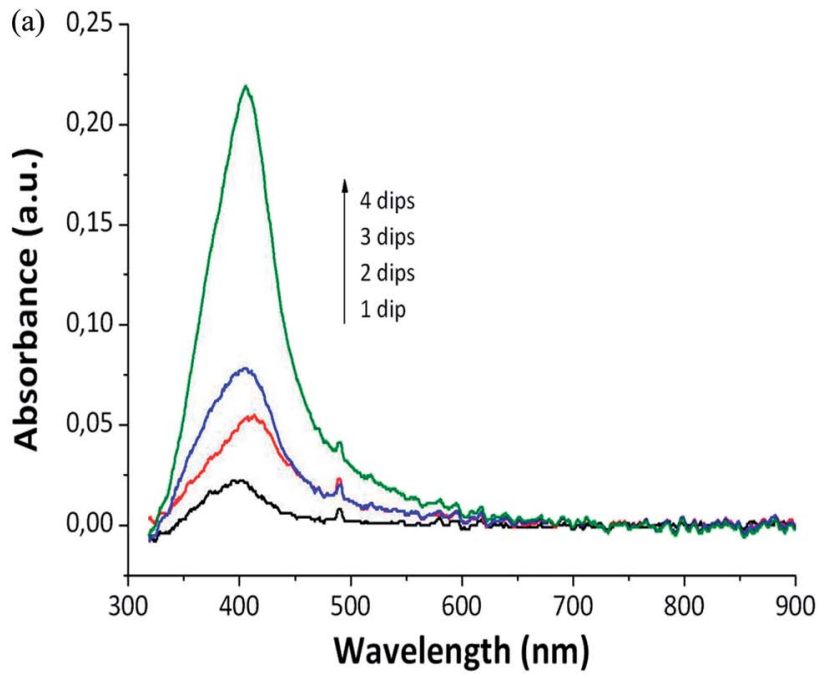

(b)

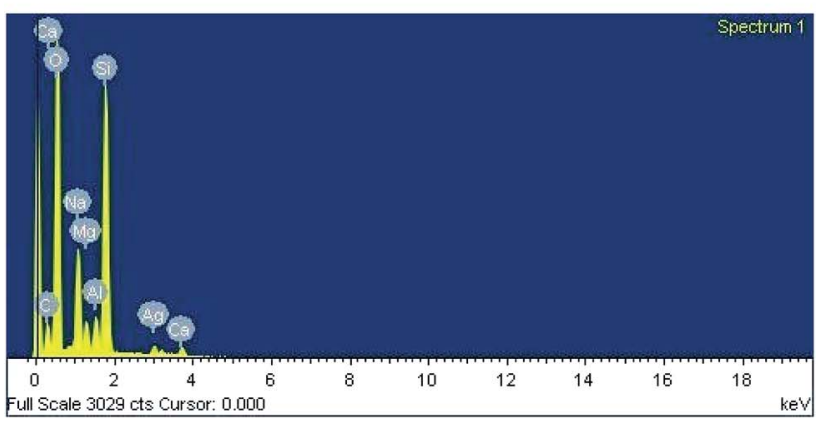

Fig. 3 (a) UV-Vis absorption spectra of the coating with different numbers of loading/reduction cycles; (b) EDX image of the coating with 4 dip/reduction cycles (PAA $20 \mathrm{mM})^{29}$ (adapted with permission from SpringerNature, 2011).

can be formed in an aqueous medium at an ambient pressure and low temperature; this approach is called the green approach. $^{33 a}$ In addition, bio-molecular recognition is considered as a special case of the adsorption of polymers; ${ }^{33 b}$ thus, the interactions between surfaces and biomaterials play a special role in both natural and industrial processes: the earliest forms of life might have been formed through the assembly of molecules on clays; the adsorption-desorption of proteins plays a fundamental role in the regulation of metabolism, control of diseases, and repair of damaged tissues. Drug delivery, design of biocompatible materials for prostheses, and protein purification are just a few examples of industrial importance where protein adsorption plays a fundamental role. ${ }^{33 c}$

In another study, polyvinyl sulphonate (PVS) was used as a stabilizing and capping agent to prepare antibacterial coatings involving silver nanoparticles. In addition, PVS was prepared by plasma polymerization. As the sulfonic acid groups of PVS gave a negative total charge to the nanoparticles, electrostatic binding occurred for the amine groups on the polymer surface due to the negative total charge of the sulfonic acid groups of PVS and the positive charge of the surface amine groups. $^{34 a}$

The synthetic process is quick and very easy: Within seconds from adding a reducing agent such as $\mathrm{NaBH}_{4}$, a colorless solution turned dark yellow-brown. A picture of different-sized silver nanoparticles is illustrated in Fig. 4b. An absorption peak, which is the characteristic of silver nanoparticles with different particle sizes, was observed, as shown in Fig. 4a. It is worth mentioning that there was no absorption peak higher than $450 \mathrm{~nm}$, indicating the absence of aggregation. The colloidal suspension was stable over months because there was no change in the solution color and there was no precipitation. Fig. 5 shows a demonstrative TEM image of AgNPs of various size ranges with the corresponding high-resolution (HRTEM) images and lattice fringes ( $d$-spacing). In addition, the histograms illustrate the range of particle size distribution. ${ }^{34 b}$

Most polydisperse and spherical nanoparticles were formed in the size range from a few nanometers to slightly above $50 \mathrm{~nm}$. The generation of effective antibacterial surfaces by coupling to polymer surface interlayers through a physical electrostatic force was focused on. PVS maintained the stability of the colloidal solution for a long time, preventing the aggregation and precipitation of AgNPs. Moreover, Fig. 6 shows the TEM images of partly sulfidized Ag-NPs.

Surface attachment via covalent bonding. Covalent bonding (grafting process) of polymers can provide a new strategy to form environmentally stable and quite-defined coating composites (polymer/nanosilver) for a long-term use. It was noticed that different chemical functional groups could be embedded in the polymer coatings using organic synthesis methods for the incorporation of nanosilver particles. ${ }^{27}$ However, there is one disadvantage of this approach, where the covalent attachment is restricted to the limited number of substrates; thus, new surface attachment techniques are needed to cover other different substrates. Fig. 7 shows the grafting process. To form imines, the aldehydes from oxidized dextran reacted with the amines from the surface, which were reduced to amines with sodium cyanoborohydride.

Accordingly, the existence of AgNPs can increase the film thickness. The water contact angle of the hydrophilic dextran was 20, as recorded for DEX-Ag. This result demonstrated that AgNPs were mostly located inside the dextran coating.

Fig. 8 shows the UV spectra of the prepared films. Due to the change in refractive index, the wavelength shifted from $400 \mathrm{~nm}$ for surface Plasmon resonance-modified surfaces of silver to $412 \mathrm{~nm}$ in solution. The dispersion/aggregation of nanoparticles could be reflected by the breadth of the UV-Vis spectra according to the concentration of $\mathrm{AgNO}_{3}$. Fig. 9 shows larger irregular aggregates of AgNPs in DEX-Ag5, but small AgNPs with uniform dispersion and aggregates of moderate sizes were present in the film of DEX-Ag2. ${ }^{35}$

The adsorption of different building blocks using the electrostatic force is the basis of the layer-by-layer self-assembly (LBL) approach that is used for the fabrication of functional ultra-thin film coatings. ${ }^{36}$ The advantages of this approach are as follows: 

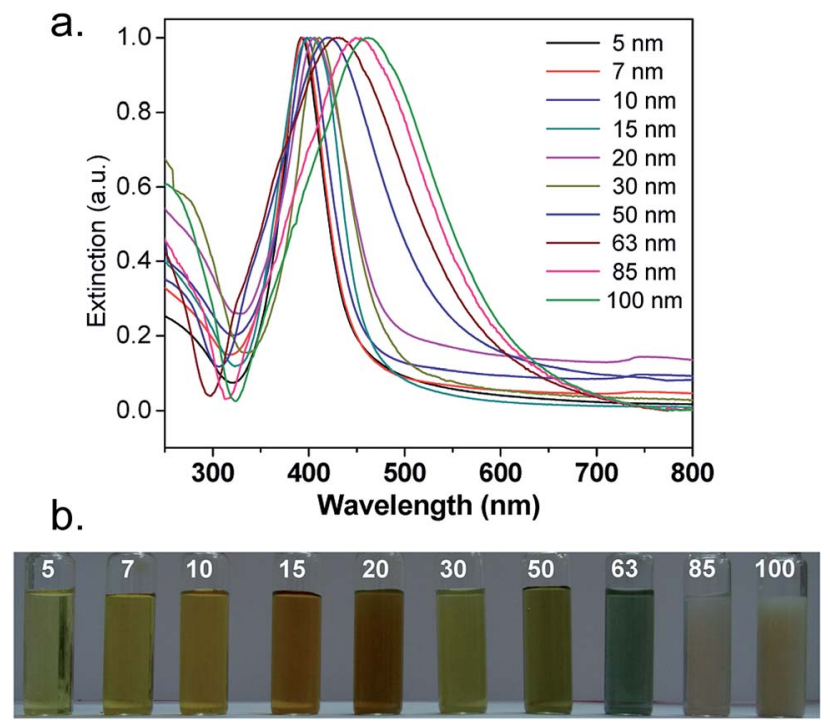

Fig. 4 (a) UV-Vis extinction spectra and (b) the distinctive color of different-sized silver nanoparticles ${ }^{34 b}$ (adapted with permission from Royal Society of Chemistry, 2013).

(1) poly-electrolytes, nanoparticles, and bio-macromolecules can be used as different building blocks; (2) we can practically adopt any substrate with any geometry and chemical composition; (3) the molecular level of chemical composition and nanostructure can be observed; (4) this approach is simple, inexpensive, and eco-friendly. ${ }^{37}$ The LBL approach is a preferred coating method for the production of polymers with nanosilver composites. Moreover, Fig. 10 summaries the different routes of coating via polymerization methods.

In their work, through the use of a layer-by-layer (LbL) nanofabrication technique, nanoparticle surface modification chemistry, and nanoreactor chemistry, Li et al. constructed thin film coatings with two distinct layered regions: a reservoir for the loading and release of bactericidal chemicals and a nanoparticle surface cap with immobilized bactericides. This resulted in dual-functional bactericidal surfaces bearing both chemical-releasing bacteria-killing capacity and contact bacteria-killing capacity. ${ }^{28}$

Scheme 2 shows the release of silver ions on a polystyrene surface and the formation of a two-level dual-functional antibacterial coating with immobilized quaternary ammonium salts. The reservoir region was made of 20 bilayers of polyallylamine hydrochloride ( $\mathrm{PAH}$, red lines) and polyacrylic acid (PAA, blue lines); through polyelectrolyte LbL deposition, the cap region made of 10 bilayers of PAH $(\sim 20 \mathrm{~nm}$ in diameter) and silica nanoparticles $\left(\mathrm{SiO}_{2} \mathrm{NPs}\right)$ could be built. ${ }^{28}$ The loading of silver into the reservoir was achieved by merely dipping the coated substrate into the solution of silver acetate. The carboxylate-bound $\mathrm{Ag}^{+}$ions could be reduced to zero-valent AgNPs after using a dimethylamineborane complex (DMAB) aqueous solution as the reductant. ${ }^{28,38,39 a}$ The carboxylic acid sites were also regenerated by the reduction reaction, making the reservoir able to be "reloaded" by the repeated loading of $\mathrm{Ag}^{+} / \mathrm{AgNPs}$ and several reduction cycles to embed a suitable amount of $\mathrm{Ag}$ inside the coating. ${ }^{28}$

As shown in Fig. 11, the cross-sectional TEM images demonstrate that AgNPs were positioned around interfaces near the interface of the reservoir/cap and mostly in the cap region; some were placed near the reservoir/substrate interface. In the case of wet-phase reduction, more mobility to the nanoparticles was provided during the bulging of multilayers with water. ${ }^{28}$

2.1.2 Sol-gel method. The sol-gel method is one of the well-established synthetic approaches to prepare novel metal oxide NPs as well as mixed oxide composites. This method has potential control over the texture and surface properties of the materials. The sol-gel method mainly requires few steps to deliver the final metal oxides and these are hydrolysis, condensation, and drying. ${ }^{39 b}$ Initially, the corresponding metal precursor undergoes rapid hydrolysis to produce a metal hydroxide solution, followed by immediate condensation, which leads to the formation of a three-dimensional gel. Afterwards, the obtained gel is subjected to the drying process, and the resulting product is readily converted to a xerogel or aerogel based on the mode of drying. The sol-gel method can be classified into two routes, i.e., aqueous sol-gel and nonaqueous solgel methods depending on the nature of the solvent utilized. ${ }^{39 b}$

The sol-gel method can be used to form undoped and Agdoped $\mathrm{TiO}_{2}$ nanocomposites. In this method, at room temperature, $2.5 \mathrm{~mL}$ of tetrabutylorthotitanate (ТВОT) was added dropwise to a solution of $2.5 \mathrm{~mL}$ acetylacetone (AcAc) and $10 \mathrm{~mL}$ ethanol and stirred for $30 \mathrm{~min}$. Afterwards, $2.0 \mathrm{~mL}$ of deionized water was added to the above solution, the $\mathrm{pH}$ was modified to 1.8 with $\mathrm{HCl}$, and $\mathrm{AgNO}_{3}$ was added (as a source of $\mathrm{Ag}$ ) to the prepared solution. After $2 \mathrm{~h}$ of stirring, a stable sol was finally formed. The solution was heated on a steam bath and then, the concentrated solution was placed for $48 \mathrm{~h}$ at $60^{\circ} \mathrm{C}$. By annealing the dried solution for $1 \mathrm{~h}$ at $500{ }^{\circ} \mathrm{C}$, two types of $\mathrm{Ag} / \mathrm{TiO}_{2}$ compounds were obtained: dried bulk powders and pure $\mathrm{TiO}_{2}{ }^{40 a}$

The XRD patterns of pure $\mathrm{TiO}_{2}, \mathrm{Ag} / \mathrm{TiO}_{2}$ and $\mathrm{Ag} / \mathrm{PEG}-\mathrm{TiO}_{2}$ nanocomposites were studied. For all samples, the (101), (004) and (200) diffraction peaks appeared at $2 \beta$ values of $25.5^{\circ}, 38.0^{\circ}$ and $48.3^{\circ}$, respectively. It could be observed that all pure and doped samples were well crystallized and the only ingredient of the nanocrystals was the anatase phase. The authors noticed that $22.10,18.50$ and $17.23 \mathrm{~nm}$ are the average crystal sizes of pure $\mathrm{TiO}_{2}, \mathrm{Ag} / \mathrm{TiO}_{2}$ and $\mathrm{Ag} / \mathrm{PEG}-\mathrm{TiO}_{2}$, respectively. It was found that the particle size decreased due to Ag addition.

Fig. 12 shows SEM images of the different shapes of silver nanoparticles fabricated through easy wet chemical methods. Regarding the study of $\mathrm{Ag} / \mathrm{PEG}-\mathrm{TiO}_{2}$, it was found that the nanocomposite powders presented very rough surface morphologies, which indicated the existence of very large pores in the matrix. Thus, the specific surface areas of pure $\mathrm{TiO}_{2}$ powders possessed more reactive sites contributing to the photoreaction because they had a smaller size than the nanocomposite powders of $\mathrm{Ag} / \mathrm{PEG}-\mathrm{TiO}_{2} \cdot{ }^{40 a}$ Near the surface of the 

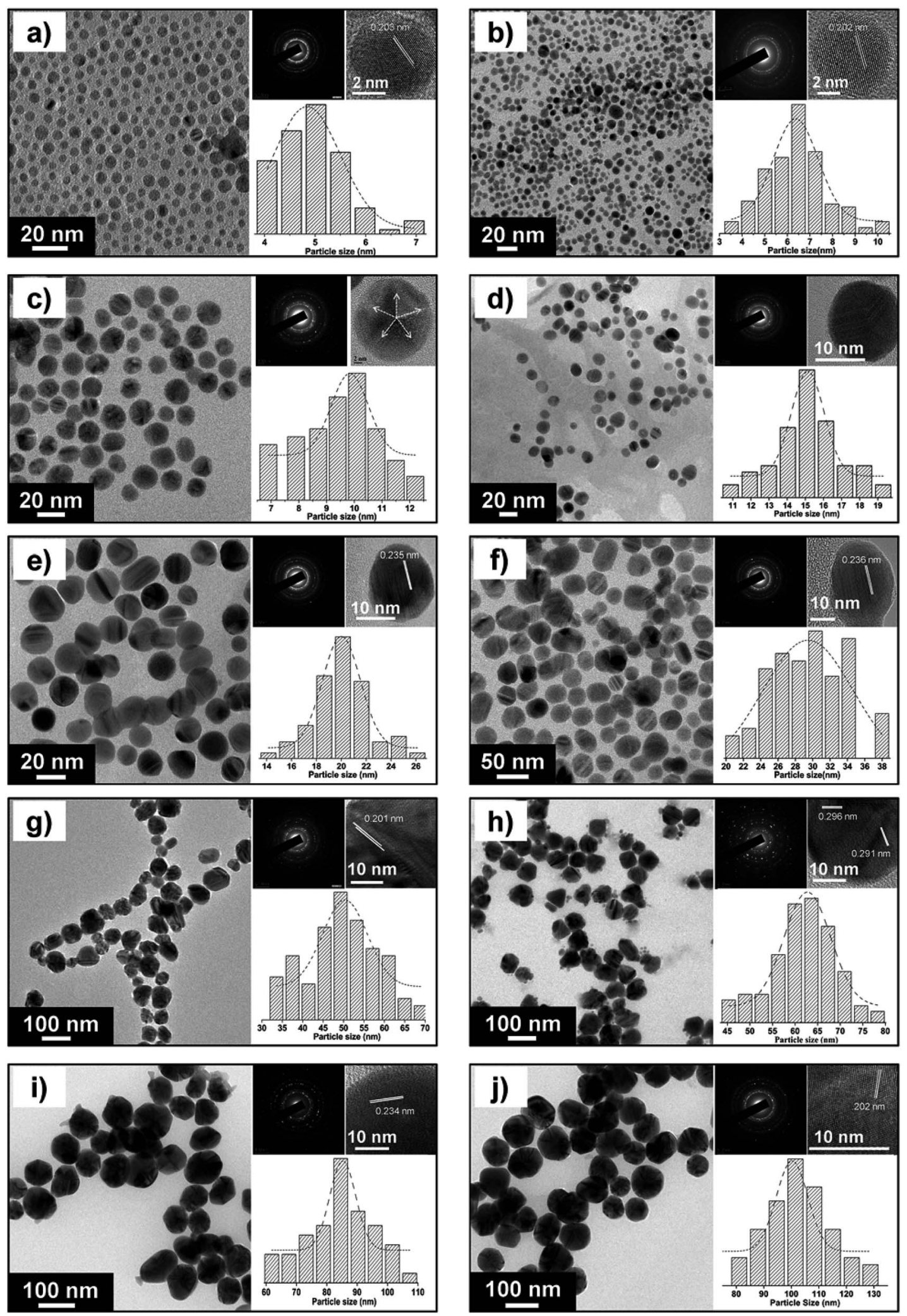

Fig. 5 FEG-TEM images of silver nanoparticles of various size ranges: (a) $5 \pm 0.7 \mathrm{~nm}$, (b) $7 \pm 1.3 \mathrm{~nm}$, (c) $10 \pm 2.0 \mathrm{~nm}$, (d) $15 \pm 2.3 \mathrm{~nm}$, (e) $20 \pm$ $2.5 \mathrm{~nm}$, (f) $30 \pm 5.1 \mathrm{~nm}$, (g) $50 \pm 7.1$, (h) $63 \pm 7.6$, (i) $85 \pm 8.2$ and (j) $100 \pm 11$.2. For each image, the corresponding high resolution (HRTEM) image and lattice fringes ( $d$-spacing) are shown. The histograms show the range of particle size distribution ${ }^{34 b}$ (adapted with permission from Royal Society of Chemistry, 2013). 


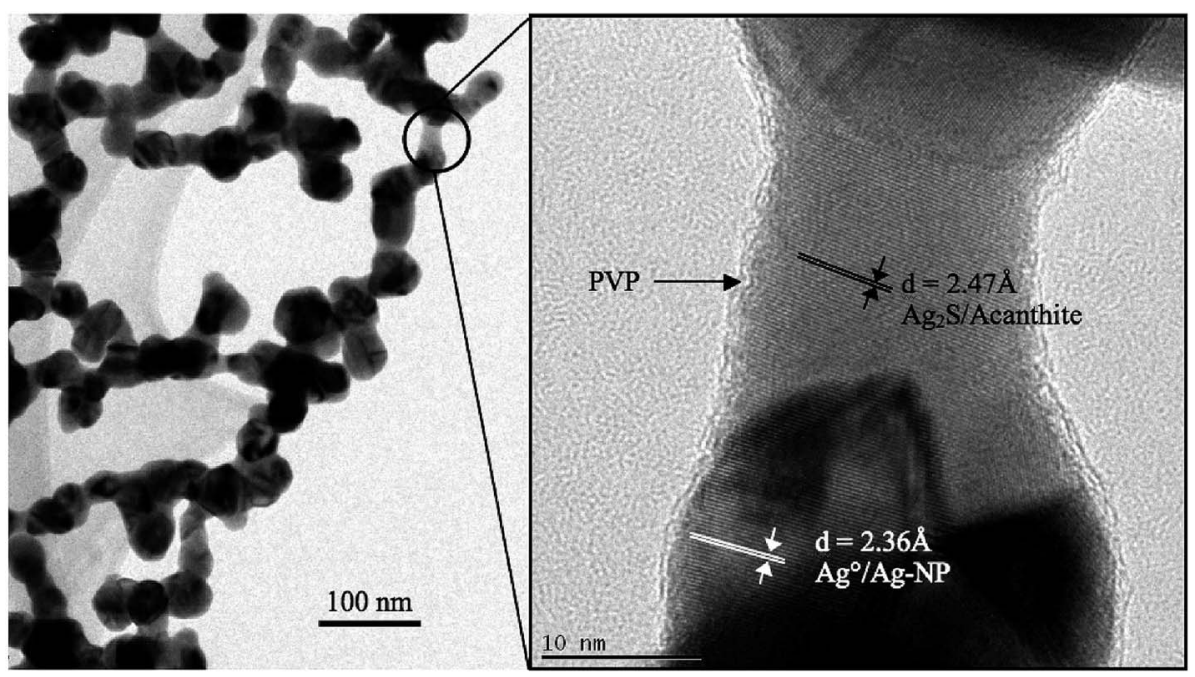

Fig. 6 TEM images of partly sulfidized Ag-NPs. The right image is at higher magnification and is centered on one of the nanobridges observed at low magnification (left image) ${ }^{34 c}$ (adapted with permission from American Chemical Society, 2012).

nanocomposite film, high loading of silver nanoparticles was embedded; they could be released when required for extended time. In addition, Scheme 3 illustrates the graphical representation of the synthesis of shape-specific silver nanoparticles using a green synthesis approach. ${ }^{40 b}$

Thin films based on silica prepared by the sol-gel methods (containing various amounts of AgNPs) were manufactured by spin coating on the slides of a soda-lime glass microscope. Four $\mathrm{mL}$ phenyltriethoxysilane was added to $4 \mathrm{~mL}$ ethanol to prepare the solution. Then, after stirring for 30 minutes, deionized water was added dropwise to the solution at room temperature with continuous stirring. Afterwards, various amounts of $\mathrm{AgNO}_{3}$ were added to the solution. ${ }^{41}$ Solutions with lower Ag concentrations require several hours to be ready for coating, while solutions with higher Ag concentrations need a shorter time. ${ }^{42}$
Fig. 13A shows a schematic of the preparation of silver nanocomposites containing $\mathrm{mSiO}_{2} @ \mathrm{NH}_{2} @ \mathrm{Ag}$, which before and after immersion in water were dried at $100{ }^{\circ} \mathrm{C}$ to control the concentration of silver nanoparticles in the matrix. Adding $\mathrm{NH}_{2}$ to the $\mathrm{mSiO}_{2}$ microspheres allowed the absorption of the maximum amount of silver ions through the complex and electrostatic interactions between $\mathrm{Ag}^{+}$ions and amino functional groups. Beyond this limit, increasing the concentration led to loose semi-spherical silver particles and the accumulation of particles. Annealing the samples for $2 \mathrm{~h}$ at $200{ }^{\circ} \mathrm{C}$ solved the problem of particle accumulation. Fig. 1B and C show the SEM and TEM (inset) images of $\mathrm{mSiO}_{2} @ \mathrm{NH}_{2} @ A g$. As seen in the TEM image, the ordered nanoporous $\mathrm{SiO}_{2}$ layers are uniformly coated on the $\mathrm{SiO}_{2}$ core surface with thickness of $c a .30 \mathrm{~nm}$ and the nanopore channels are perpendicular to the microsphere surface. The

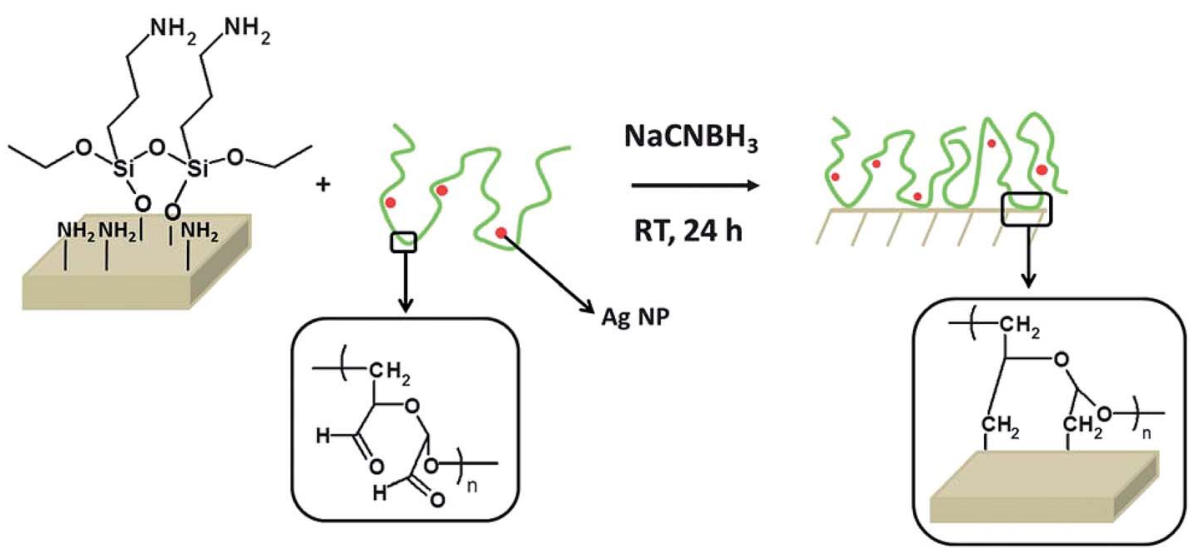

Fig. 7 The grafting process: previously aminated surfaces are immersed into a DEX solution containing AgNPs (DEX-Ag solution). The aldehydes present in DEX react with the amines to form imines, which are further reduced to amines with sodium cyanoborohydride. As the reaction proceeds, the AgNPs are entrapped in the DEX network, which is covalently attached to the surface ${ }^{35}$ (adapted with permission from Royal Society of Chemistry, 2011). 

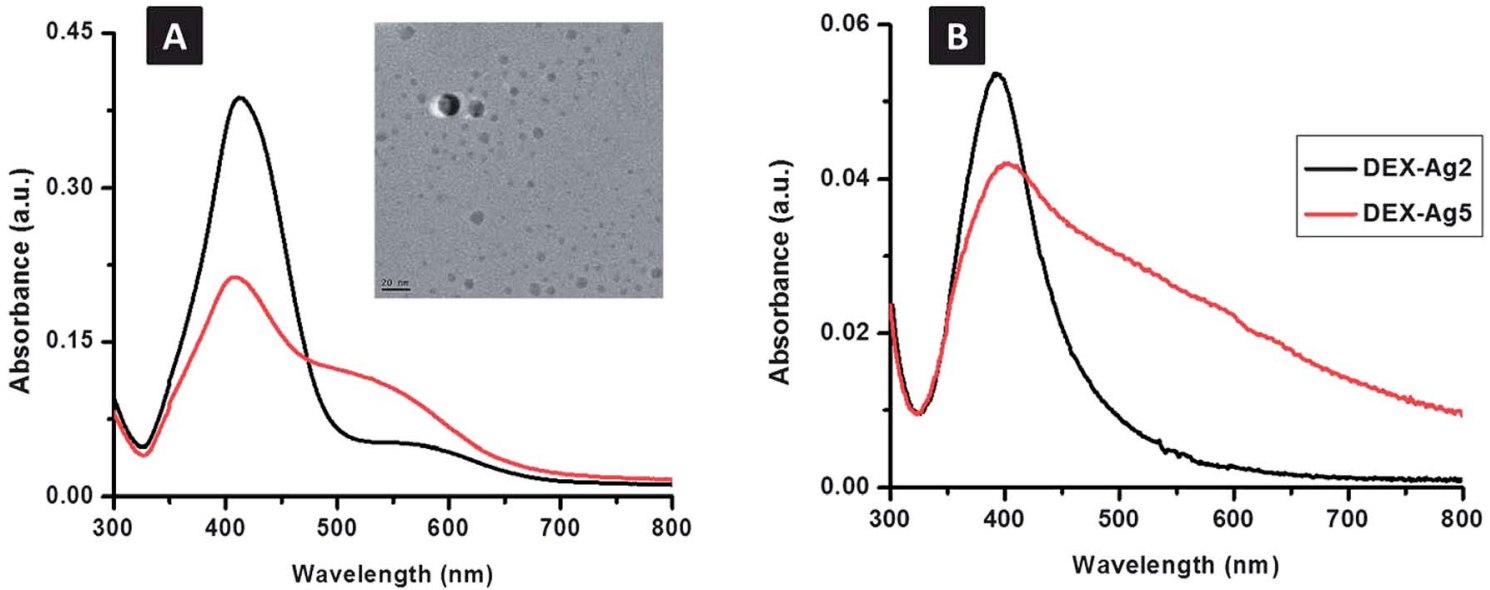

Fig. 8 UV-Vis spectroscopy of silver embedded in dextran (DEX-Ag); concentrations of silver nitrate of $2 \mathrm{mM}$ and $5 \mathrm{mM}(\mathrm{A})(\lambda=412 \pm 2 \mathrm{~nm})$ in solution and (B) $(\lambda=400 \pm 5 \mathrm{~nm})$ grafted on to the surface of DEX-Ag2 and DEX-Ag5, respectively. The peaks are related to the silver surface plasmon resonance. The sharp peak of DEX-Ag2 is related to the distribution of particles with narrow size; however, in the case of DEX-Ag5, a broader band appears. When compared to the solution, DEX containing AgNPs attached onto the surface results in a slight blue shift. The TEM micrograph shows spherical particles (scale bar, $20 \mathrm{~nm}$ ) of AgNPs embedded in DEX-Ag2, where $4.8 \pm 2.6 \mathrm{~nm}$ is the average diameter of the AgNPs $^{35}$ (adapted with permission from Royal Society of Chemistry, 2011).

number of surface particles only reduced slightly and the cluster became semi-spherical, as shown in Fig. 13B. After 15 days immersion in deionized water, the number of particles considerably reduced but there was some nanosilver still left on the film surface, as shown in the SEM images in Fig. 13B. ${ }^{41}$
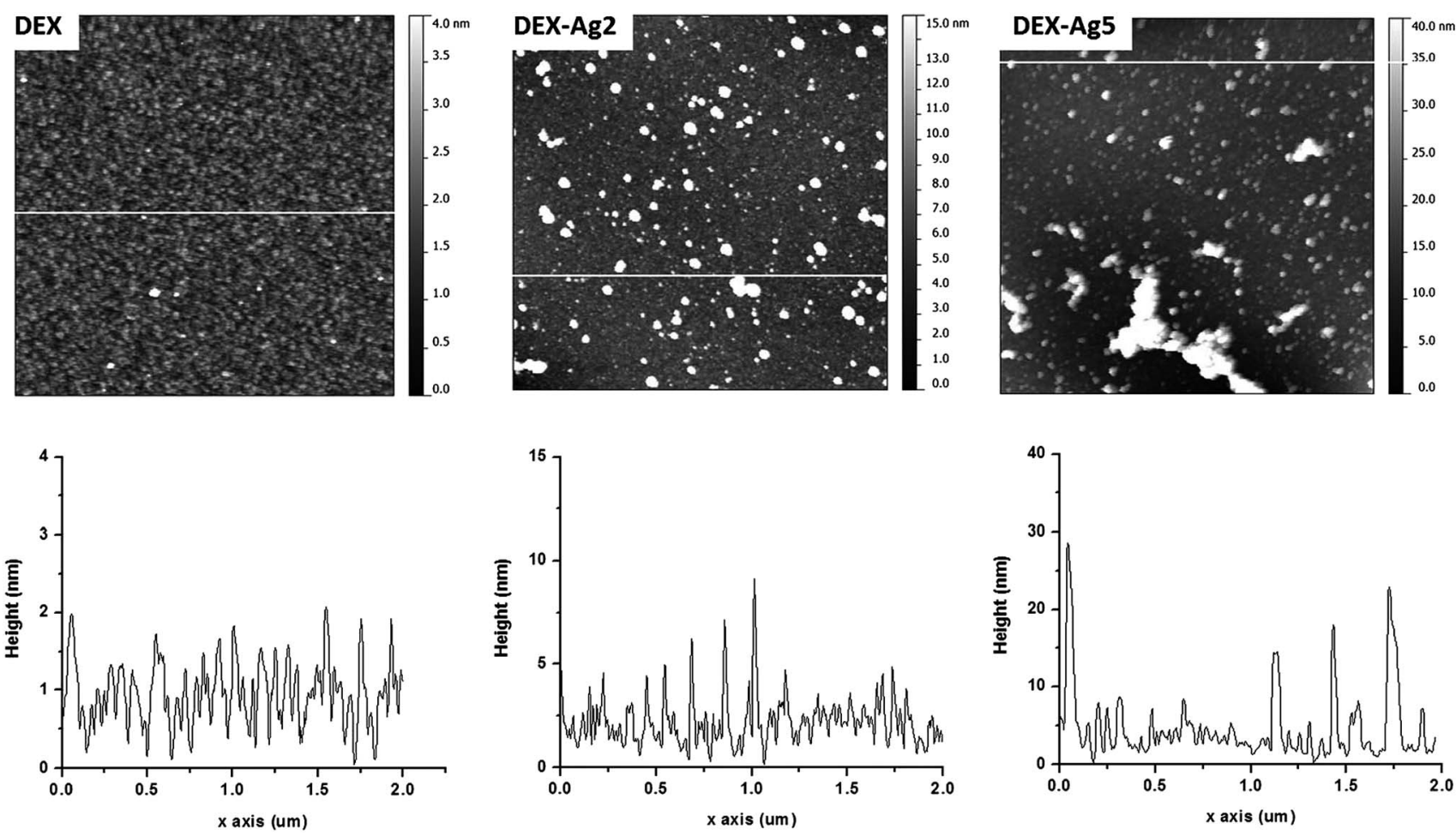

Fig. 9 Top: AFM topography images of grafted DEX (DEX) and grafted DEX with trapped AgNPs prepared using concentrations of 2 mM (DEXAg2) and $5 \mathrm{mM}$ (DEX-Ag5). The scan size is $2 \times 2 \mu \mathrm{m}^{2}$. The grafted dextran surface shows a uniform distribution of $\sim 50 \mathrm{~nm}$ features and $2 \mathrm{~nm}$ height across a relatively smooth surface. Individual AgNPs $(\sim 5 \mathrm{~nm})$ and clusters distributed across the film uniformly on the surfaces containing grafted dextran. In the case of DEX-Ag5, aggregates of irregular and larger shapes are observed. The $z$ scales are $4 \mathrm{~nm}, 15 \mathrm{~nm}$ and $40 \mathrm{~nm}$ for DEX DEX-Ag2 and DEX-Ag5 respectively. Bottom: a line scan across the white line of the corresponding upper image of topography ${ }^{35}$ (adapted with permission from Royal Society of Chemistry, 2011). 


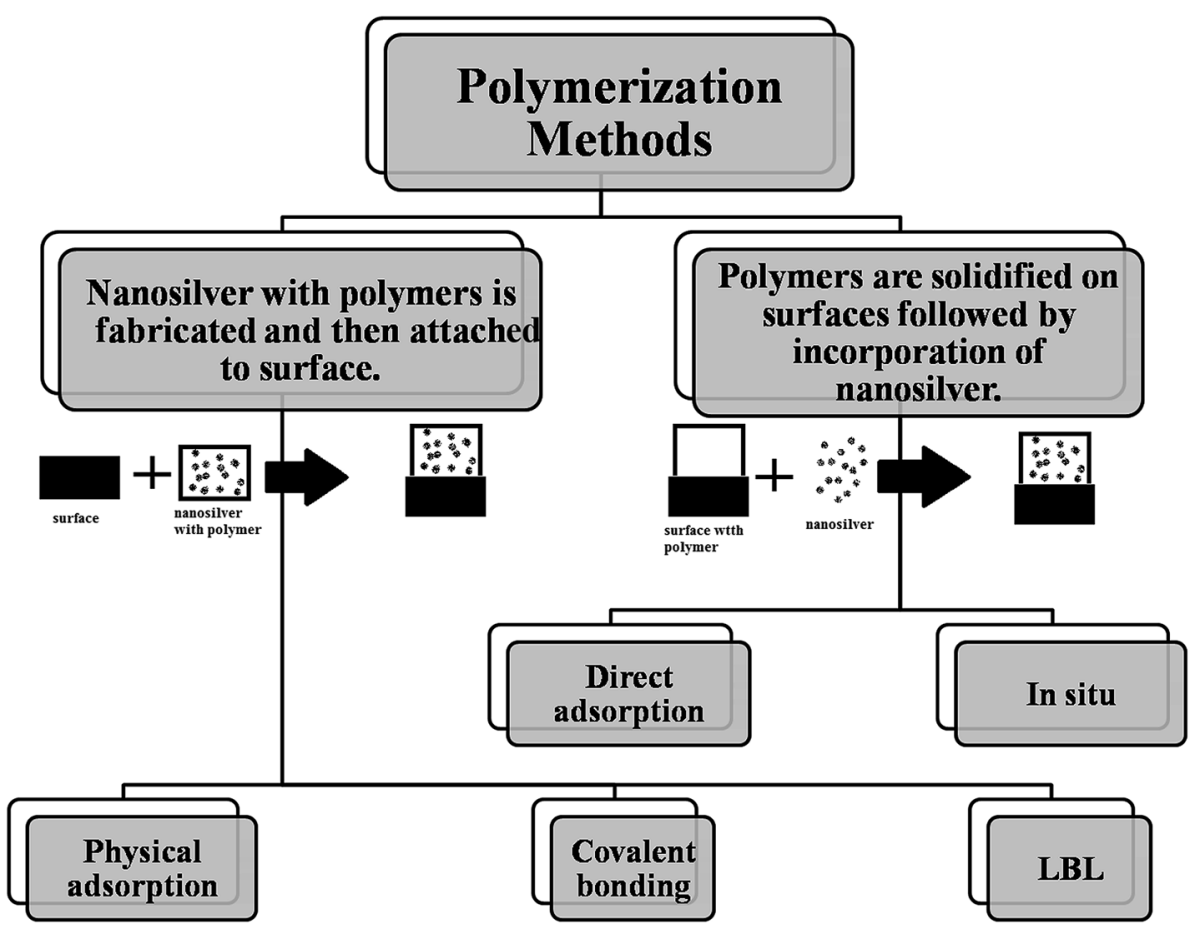

Fig. 10 The different routes of coating via polymerization methods. "LBL; layer-by-layer".

It was found that the self-accumulation of AgNPs on the dried film surface and the diffusion of Ag particles inside the film occurred at a higher temperature. For the cases before and after immersion in DI water, the Ag (3d) core-level XPS spectrum of the silver-containing coating is shown in Fig. 14. It was observed that $368.5 \mathrm{eV}$ and $374.5 \mathrm{eV}$ are the binding energies of $A g\left(3 d_{5 / 2}\right)$ and $A g\left(3 d_{3 / 2}\right)$ peaks, respectively, and $6.0 \mathrm{eV}$ is the splitting of the $3 \mathrm{~d}$ doublet of $\mathrm{Ag}$. This difference of splitting confirmed the formation of metallic silver nanoparticles..$^{43}$ After immersion, water could be absorbed by the silver-containing coating into the film, and silver nanoparticles were ionized. ${ }^{44}$

\subsection{Core-shell coating materials}

The core or the shell substances determine the core-shell nanostructure properties. We can control the core-shell function by changing the constituting materials or the ratio of the core to the shell. The functions of the coating

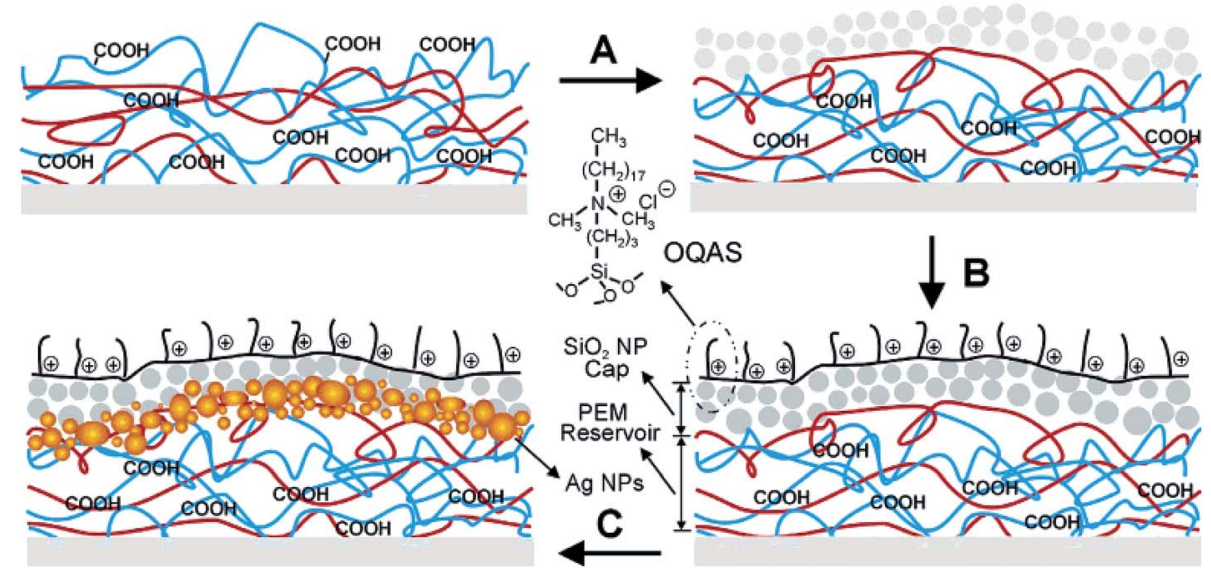

Scheme 2 Two-level dual-functional antibacterial design of coating with silver and quaternary ammonium salts. The coating process begins with the $\mathrm{LbL}$ deposition of a reservoir made of bilayers of PAH and PAA. (A) A cap region made of bilayers of $\mathrm{PAH}$ and $\mathrm{SiO}_{2} \mathrm{NPs}$ is added on the top. (B) The $\mathrm{SiO}_{2}$ NP cap is modified with a quaternary ammonium silane, OQAS. (C) $\mathrm{Ag}^{+}$can be loaded inside the coating using the available unreacted carboxylic acid groups in the LbL multilayers. Ag NPs are created in situ using the nanoreactor chemistry described previously ${ }^{28}$ (adapted with permission from American Chemical Society, 2006). 


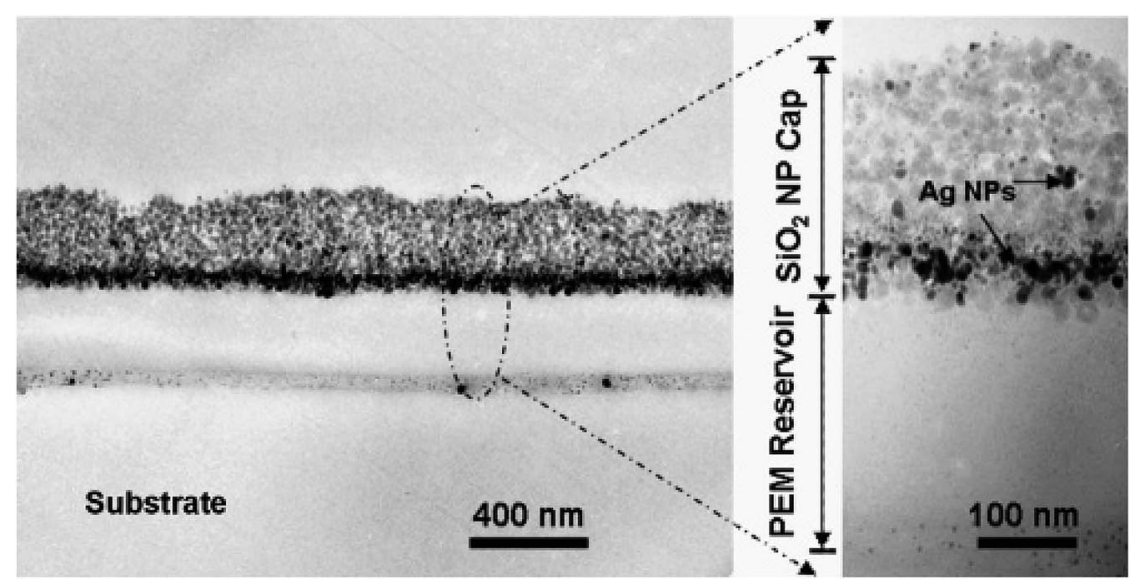

Fig. 11 Cross-sectional TEM images showing the two-level antibacterial coating with OQAS and silver. AgNPs resulting from two Ag loading and reduction cycles were embedded inside coatings by a wet-phase reduction method using a complex solution of dimethylamineborane (DMAB) ${ }^{28}$ (adapted with permission from American Chemical Society, 2006).

substances involve increasing stability, controlled release of the core material or functionalization. The core-shell nanostructures are mainly used in bioimaging, drug delivery, controlled release of the drug, and other bio-medical applications. ${ }^{45}$

The core-shell nanoparticles can be classified according to the type of the coating substances into two classes: organic and inorganic. ${ }^{46}$

The organic NPs are related to the carbon-based compounds, usually polymers, while the inorganic NPs are usually metalbased compounds and can be sub-classified into metal nanoparticles, metal oxide nanoparticles, and metal salts. Generally, metal nanoparticles are synthesized by the reduction of their metal salts. ${ }^{9}$

2.2.1 Organic-coated NPs. Ionization and clustering of AgNP surfaces over a long period usually occurs, leading to decrease in the functionalization of the surface; coating them using the layer-by-layer technique with an organic material (e.g., thiol-derivatives, xanthate, etc.) plays an important role in shielding against ionization processes. ${ }^{47-49}$

AgNPs are special materials because they have exceptional chemical and physical properties in addition to the low cost. Coating of AgNPs in a uniform manner (using the insulator material as silica) enhances their optical properties, ${ }^{50-53}$ dispersibility, ${ }^{54}$ and inertness ${ }^{55}$ and lowers cytotoxicity, which facilitate biological applications. Hardikar and Matijević demonstrated a simple method for coating silver particles using the Stöber method with some modifications to control the thickness of the shell over a period of 2-3 h, and to increase the stability of the system (in water or in isopropanol) for six months. ${ }^{56}$ The laser ablation-assisted chemical reduction method to has an advantage: on top of metallic nanoparticles, a silica shell is directly formed without any passivation step. ${ }^{57}$

2.2.2 Non-organic-coated NPs. Different applications were noticed in several fields for non-organic-coated nanomaterials, such as solid state electronics, televisions and computers. In addition, we recognized that these substances could be used in the field of biomedical science as well as in coating depending on their different configurations. These nanomaterials are defined as any structure that has all three of its dimensions in the nanoscale. Nanomaterials are often tailored in different shapes, sizes, and compositions for different functions in many applications such as health care, biosensing, drug delivery, medical imaging and coatings. Moreover, many types of these non-organic substances are used for material coatings such as metal, bimetal, metal oxide and metal-salt nanoparticles.

Metal nanoparticles. Metal nanoparticles have excellent electrical, physical, optical and chemical properties; thus, they have many applications in catalysis, optics, electronics, and biomedicine. ${ }^{58,59}$ Silver nanoparticles, for example, are one of the most commonly investigated nanomaterials due to their biocompatibility and easy surface chemistry. The unique properties of nanomaterials come from their special shapes and sizes between bulk materials, atoms and molecules.

Bimetal nanoparticles. The silver-gold (metal-metal) coreshell nanoparticles present superior optical and physical characteristics over uncoated metal nanoparticles; thus, they can be used in surface-enhanced Raman spectroscopy, photothermal therapy, and catalysis. ${ }^{60}$ The electronic, optical, catalytic and magnetic characteristics of the bimetal nanoparticles differ from those of their individual metal nanoparticles. ${ }^{45}$

Another example is silver-platinum nanoparticles; they are considered as good candidates for the coating process. There are different kinds of silver-platinum nanostructures, i.e., alloy nanoparticles ${ }^{61}$ or core-shell nanostructures, which may be silver cores coated with platinum ${ }^{62,63}$ or platinum cores coated with silver. ${ }^{64,65}$

Metal oxide nanoparticles. The metal oxide nanoparticles have excellent chemical and physical properties and play important roles in drug delivery and catalysis; they can also be used in the manufacturing of semiconductors, sensors and fuel cells. ${ }^{65}$ In biomedical applications, a silver iron oxide core-shell nanostructure allows adding a magnetic function to 

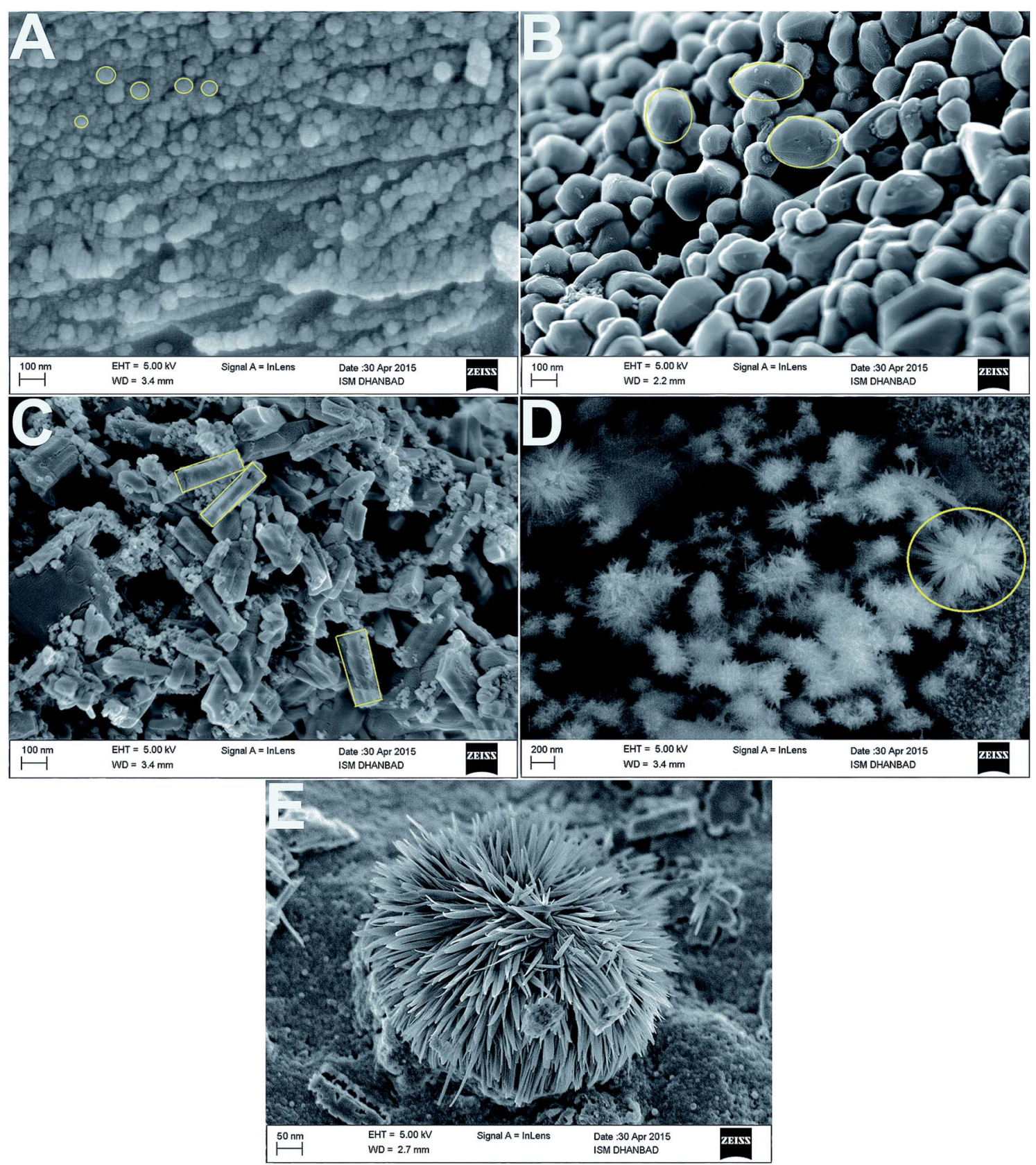

Fig. 12 FE-SEM images of the (A) spherical, (B) oval, (C) rod and (D) flower-shaped silver nanoparticles at low and (E) high magnifications ${ }^{40 b}$ (adapted with permission from Royal Society of Chemistry, 2015).

AgNPs. This nanostructure can solve the problem of the biocompatibility of AgNPs and decrease their direct contact with tissues. ${ }^{66}$

Metal salt nanoparticles. Copper sulfide is a transition metal compound that is present in nature. It has high capacity and conductivity and can be used in the manufacturing of sensors, solar cells and battery cathodes. ${ }^{67}$ A core-shell nanostructure of silver copper sulfide used as the silver nanowire increases the electrochemical processes of copper sulfide through reducing its resistance to charge transfer. ${ }^{68}$

\section{Cytotoxicity of coated and uncoated AgNPs}

AgNPs have a cytotoxic effect against mammalian cells; scientists studied the cytotoxic effect of uncoated AgNPs and the AgNPs coated with either chemical or biological substances. ${ }^{69}$ The factors contributing to the cytotoxicity of AgNPs are the shape, size, and surface charge or coating and the release of the ionic form of silver. 


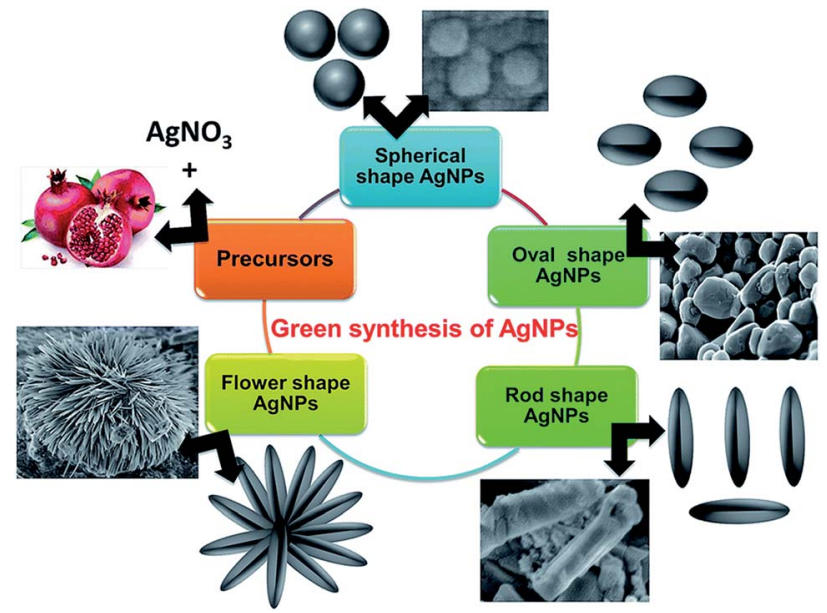

Scheme 3 Graphical representation of synthesis of shape-specific silver nanoparticles using the green synthesis approach ${ }^{40 b}$ (adapted with permission from Royal Society of Chemistry, 2015).

AgNPs may disrupt the membrane of the cell, affect the production of ATP and the replication of DNA, change the gene expression, and oxidize the biological compartments of the cell through the production of ROS. The silver ions released by AgNPs may block the respiratory chain of the microorganisms in the cytochrome oxidase and NADH-succinate dehydrogenase region. $^{70}$ The mechanisms of the action of the AgNP antimicrobial effect and the active transport of nanoparticles into cells are represented in Fig. 15 and 16, respectively.

Cytotoxicity reactions are caused by increasing the levels of reactive oxygen species, decreasing the levels of intracellular glutathione, and decreasing the potential of the mitochondria membrane. ${ }^{71}$ AgNPs can cause inflammation of the epithetical cells of lungs and macrophage inflammation. ${ }^{72}$

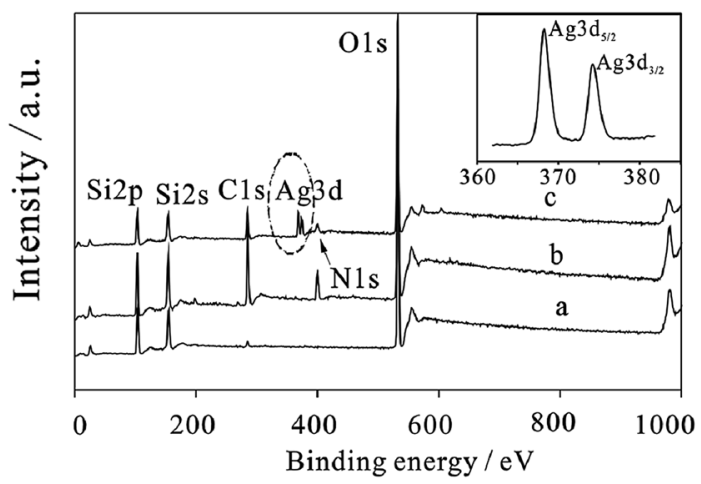

Fig. 14 XPS spectra of (a) $\mathrm{mSiO}_{2}$, (b) $\mathrm{mSiO}_{2} @ \mathrm{NH}_{2}$ and (c) $\mathrm{mSiO}_{2} \mathrm{a}-$ $\mathrm{NH}_{2} \mathrm{QAg}$; inset is the high resolution $\mathrm{Ag} 3 \mathrm{~d}$ XPS spectra of $\mathrm{mSiO}_{2} \mathrm{a}-$ $\mathrm{NH}_{2} @ \mathrm{Ag}^{41}$ (adapted with permission from Royal Society of Chemistry, 2015).

Studies show that AgNP cytotoxicity depends on the size and also on the coating substances as the size of the nanoparticles, including that of silver, is related to their uptake by the cells. ${ }^{73}$

Researchers proposed that the coating of the nanoparticle surface increases the stability and the dissolution of the nanoparticles. ${ }^{74}$ The cytotoxic effect of AgNPs depends on specific factors such as (1) size (the small particle size corresponding to the higher toxicity degree); (2) aggregation (aggregated AgNPs decrease the cytotoxic effect); and (3) coating (the coating of AgNPs usually decreases the cytotoxicity of AgNPs). ${ }^{75}$

The toxicity mechanism of AgNPs depends on their chemical attraction to the surface of the cells and the dissolution of the silver ions from the nanoparticles; the coating of the AgNPs affects their cytotoxic mechanism. ${ }^{76}$

A
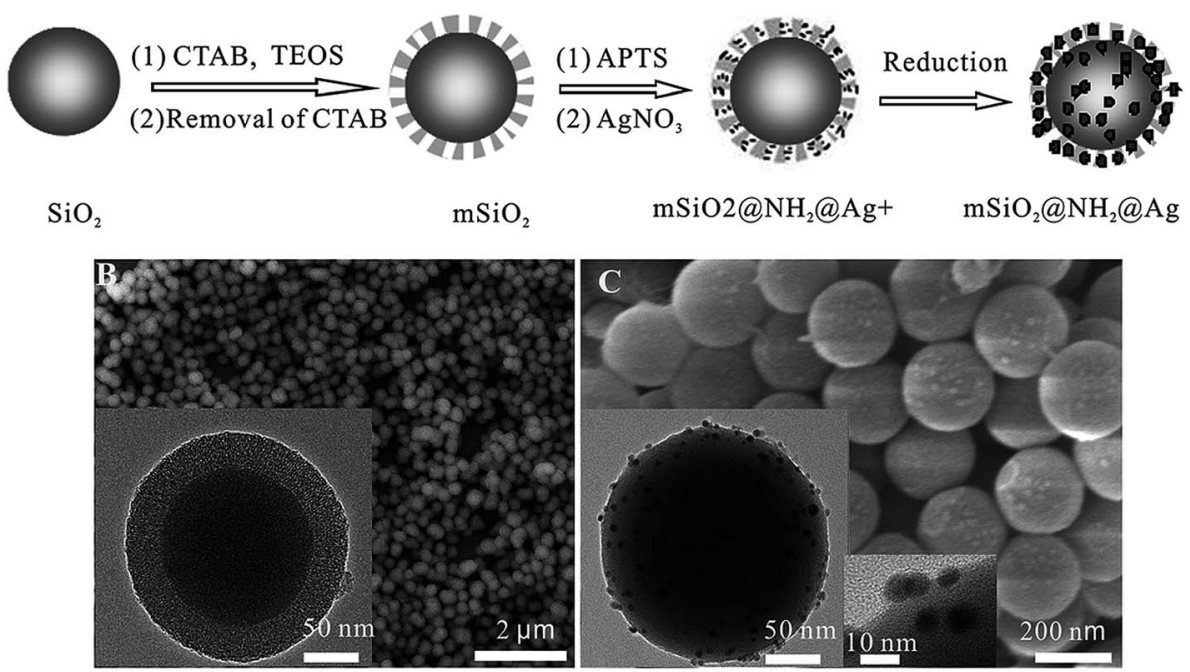

Fig. 13 (A) Schematic illustration of the procedure for the preparation of $\mathrm{mSiO}_{2} @ \mathrm{aNH}_{2} @ \mathrm{Ag}$. (B) SEM image of $\mathrm{mSiO}_{2} \mathrm{microspheres}$ (C) SEM image of $\mathrm{mSiO}_{2} @ \mathrm{NH}_{2} @ \mathrm{Ag}$. The insets show the low-magnification and high-magnification TEM images of $\mathrm{mSiO}_{2} @ \mathrm{NH}_{2} @ \mathrm{Ag}^{41}$ (adapted with permission from Royal Society of Chemistry, 2015). 


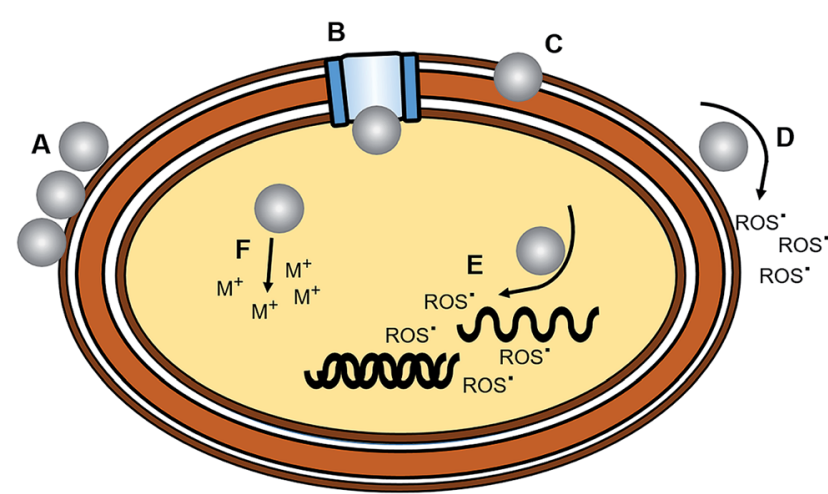
A. Accumulation of nanoparticles on the outer cell membrane
B. Cellular internalisation via damage to the membrane
C. Cellular internalisation via endocytosis
D. Extra-cellular ROS generation
E. Intracellular ROS generation
F. Generation of toxic metal ions

Fig. 15 Schematic representation of the mechanisms of action of the AgNP antimicrobial effect ${ }^{79 b}$ (adapted with permission from American Chemical Society, 2019).

The surface area and the size are also major factors that are used to determine the levels of cytotoxicity; therefore, the coating material can affect the cytotoxicity mechanism as it can perfectly affect the surface area, shape and physical properties. ${ }^{77}$

The cytotoxicities on silver nitrate and the other three types of AgNPs were studied when coated with different coating substances (PVP, CTAB, and citrate) spread of Allium cepa roots. Their study confirmed that all the investigated AgNPs caused oxidative stress and showed that the uncoated silver is highly toxic than the coated one, affirming that the cytotoxicity also depends on the concentration of the nanoparticles. ${ }^{78}$ In another study, the synthesized silver nanoparticles (using biological synthesis) coated with zinc oxide decreased the cytotoxicity of AgNPs against the human cancer cell line A431. ${ }^{79 a}$ The cytotoxicities of doped and undoped AgNPs with some other different parameters related to these materials are summarized in Table 1.

In addition, many groups demonstrate a concern about the cytotoxicity in vivo. As an example, Tang et al. studied the cytotoxicity in vivo and found that the power of novel vaccine strategies shows rapid and quantitative analysis through their experimental evaluation of target cells expressing a luciferase reporter gene. The experiment was set up via implanting the genes as monolayers on polystyrene disks into the muscle tissue of mice. The luciferase activity retrievable from the adjacent tissue was used as an index of cytotoxicity. The implantation of B16 or NIH/3T3 cells caused the expression of the beta-galactosidase gene and indicated that the target cells migrated to the muscle tissue from the polymer within $4 \mathrm{~h}$ and then remained localized in the area of the disk. They found that the amounts of luciferase retrievable from the adjacent tissue a few days post implantation could be readily detected by the immune response induced by the allo-immunization of fibroblasts or by the production of interleukin-4 by the tumor cells comixed with implanted reporter cells. ${ }^{79 c}$

\section{Optical properties of silver NPs}

One of the most important features of silver nanoparticles is their optical property; they can be used in many

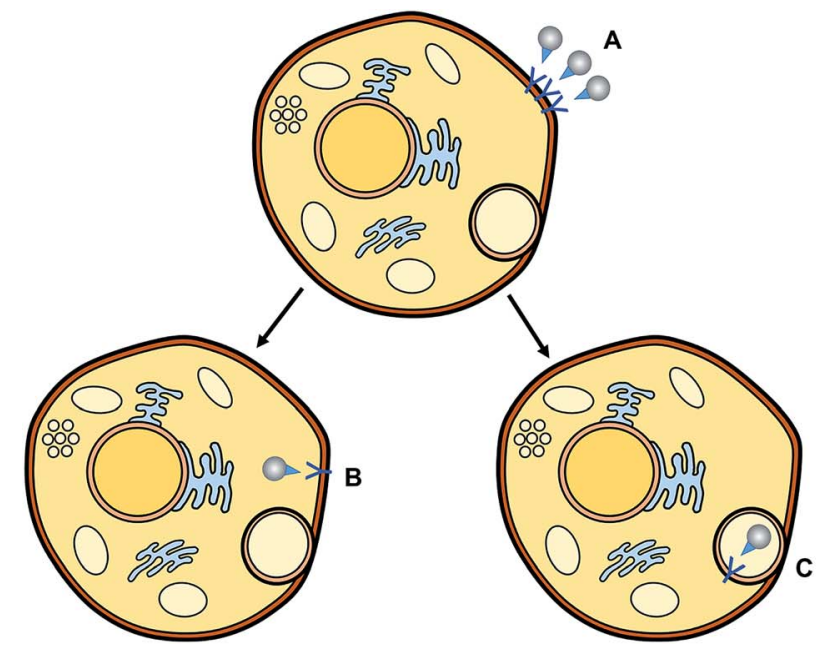
A. Nanoparticles approaching
active transport receptors
B. Receptor-mediated
translocation of nanoparticles
C. Receptor-mediated
endocytosis of nanoparticles

Fig. 16 Schematic representation of the active transport of nanoparticles into cells ${ }^{79 b}$ (adapted with permission from American Chemical Society, 2019). 
হั

$\infty$

$\stackrel{0}{\Xi}$

¿ே.

诡

政

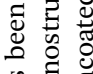

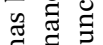

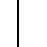

矛家

$\stackrel{\infty}{+}$

$\stackrel{4}{4}$

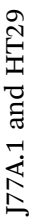

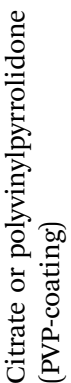

$\vec{\infty} \quad \infty$ $\infty$

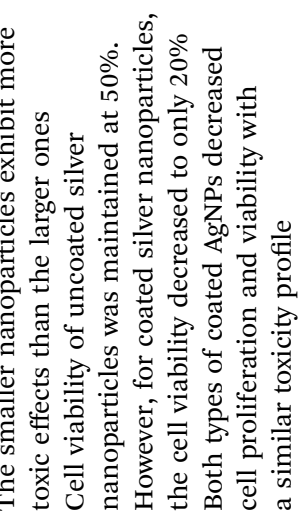

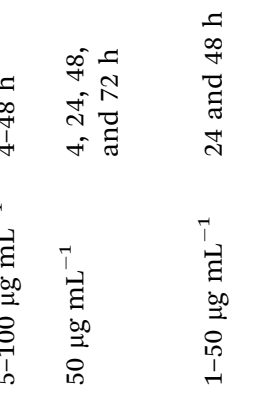

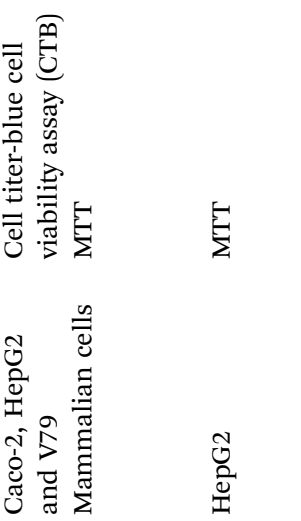

छ 요 applications owing to their absorption in a wide range of wavelengths. In recent years, there has been increasing interest in the use of nanoparticles because they have different physical, chemical and optical properties from the bulk materials. Metal nanoparticles are gaining importance, which is caused by their surface plasmon resonance (SPR), allowing higher sensitivity and a faster response as optical sensors. ${ }^{84}$

AgNPs have many potential applications in different fields due to their unique optical properties. ${ }^{85}$ The surface of AgNPs easily changes according to the weakly stabilized binding layer of ligands (as citrate); ${ }^{86,87}$ thus, these layers can be easily replaced with different materials such as organic, inorganic and polymer materials to improve the optical properties. ${ }^{88}$

A previous study suggested that in the $\mathrm{Ag} / \mathrm{ZnO}$ nanocomposite, the thin film thickness is an important factor that affects photoluminescence due to the improvement in the UV emission with an increase in the film thickness; however, it can decrease again when the thickness of the film is more than six layers. ${ }^{89}$ Direct coating of AgNPs and embedding a thin interlayer of AgNPs in a matrix of polyvinyl alcohol films can affect the optical properties. This thin interlayer can affect the microstructural and the optical properties of the thin film by lowering the optical band gap from $3.66 \mathrm{eV}$ to $3.57 \mathrm{eV}$ with the increase in temperature from $20^{\circ} \mathrm{C}$ to $200^{\circ} \mathrm{C}$, respectively..$^{90}$ In addition, to increase the chance of coated AgNPs as optical limiting materials, spherical AgNPs were prepared by using the seeding growth method; a silica coating was used to obtain an $\mathrm{Ag} / \mathrm{SiO}_{2}$ core-shell structure. Finally, $\mathrm{Ag} / \mathrm{SiO}_{2}$ was doped into polydimethylsiloxane rubbers to determine the optical limiting property to a laser at $532 \mathrm{~nm}$. It showed a great optical restricting impact, which is of high importance for nonlinear optical absorption and refraction. ${ }^{91}$

Due to the great optical properties of AgNPs, they were incorporated into an optical test strip for the quantitative determination of hydrogen peroxide $\left(\mathrm{H}_{2} \mathrm{O}_{2}\right)$ in aqueous solutions. AgNPs were synthesized by in situ reduction in a Nafion-117 membrane previously absorbed with ascorbate ions $\left(\mathrm{HA}^{-}\right)$. The quantitative determination of $\mathrm{H}_{2} \mathrm{O}_{2}$ concentration could be estimated over a wide range of concentrations by decreasing the intensity of the localized surface plasmon resonance of the membrane. Ajitha et al. studied the evaluation of PVA-capped AgNPs as LSPR-based optical hydrogen peroxide sensors with the additional advantage of lowering detection limits than the conventional enzyme-based biosensors (Fig. 17). ${ }^{92}$

Furthermore, AgNPs coated with polysaccharide dextran formed stable colloids that displayed high sensitivity and selectivity for cysteine detection in aqueous solutions among a dozen amino acids with a high detection limit $(12.0 \mu \mathrm{M}){ }^{92,93}$

Silver-carbon core/shell structures helped strengthen plasmon resonance and stability and increased the ability to adsorb proteins and other molecules on their surface by standard cross-linking, allowing them to be used in promising biological applications such as optical labeling. ${ }^{94}$ 
(a)

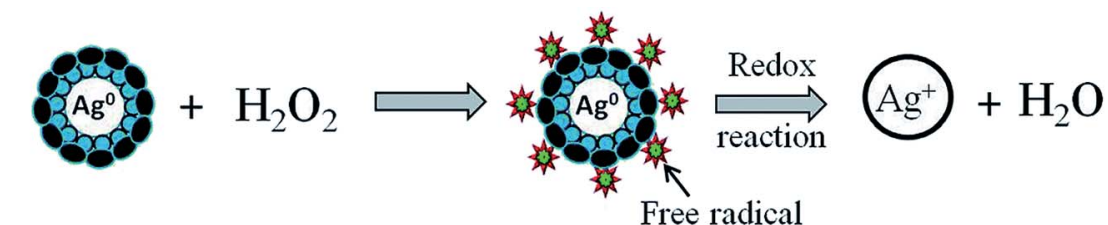

(b)
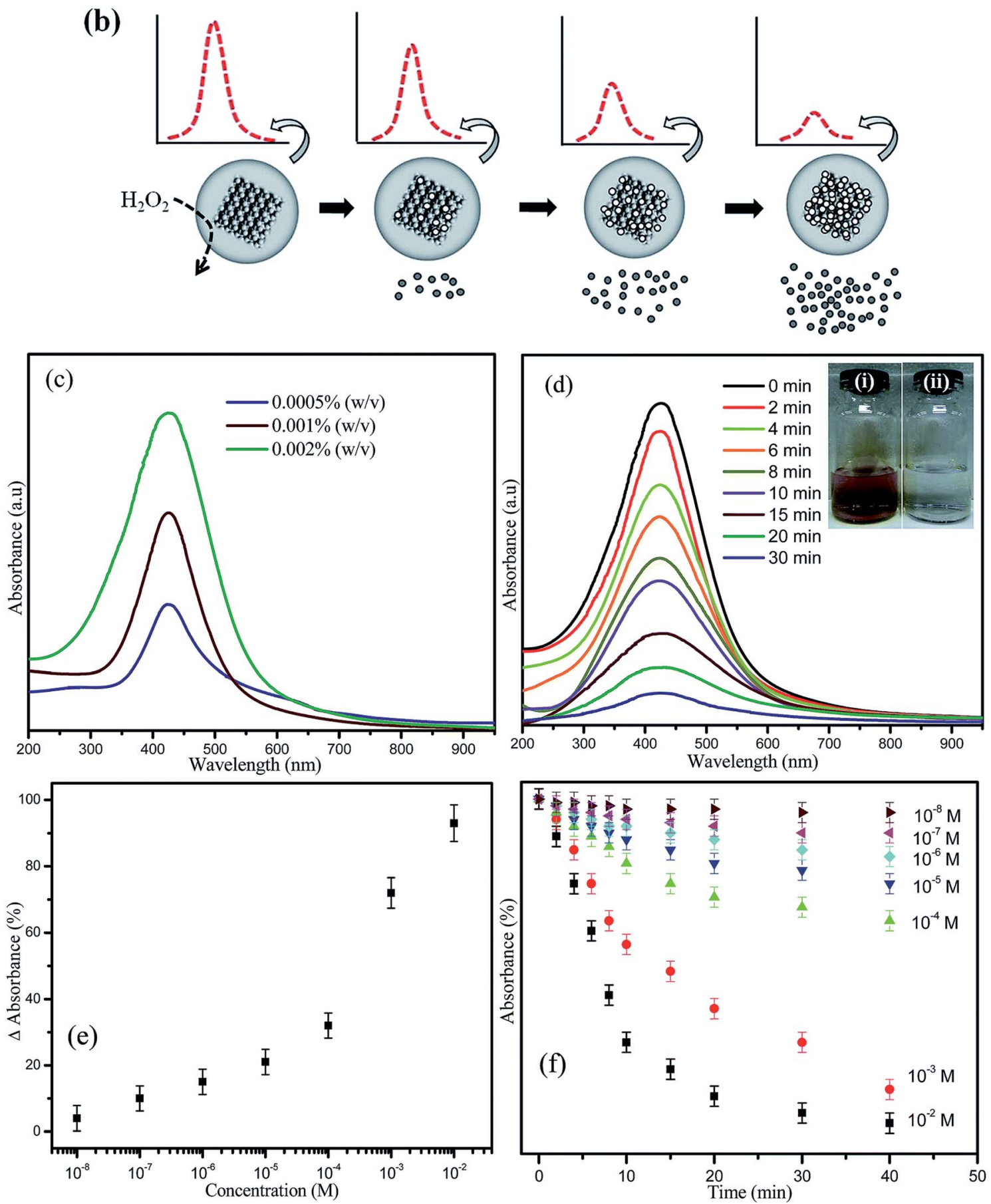

Fig. 17 Possible mechanism and schematic representation of (a) the reaction between PVA-coated AgNPs and $\mathrm{H}_{2} \mathrm{O}_{2}$ and (b) the decrease in the absorbance intensity with increasing $\mathrm{H}_{2} \mathrm{O}_{2}$ concentration. (c) Optical absorption characteristics of different concentrations of PVA-capped AgNPs. (d) LSPR optical absorbance spectra of AgNPs as a function of time after the addition of $10-3 \mathrm{M} \mathrm{H}_{2} \mathrm{O}_{2}$. (Inset: AgNP solution (i) before and (ii) after the addition of $\mathrm{H}_{2} \mathrm{O}_{2}$ ). (e) The correlation between the optical absorbance strength changes after 30 min with respect to different concentrations of $\mathrm{H}_{2} \mathrm{O}_{2}$ added to the PVA-AgNPs. (f) Relationship between the absorbance intensity and reaction time for different concentrations of $\mathrm{H}_{2} \mathrm{O}_{2}{ }^{92}$ (adapted with permission from Royal Society of Chemistry, 2016). 


\section{Conclusions}

AgNPs are widely used in electronic, antimicrobial, optical, and medical fields. Biological applications are limited in comparison with that of their counterparts in other fields due to the toxicity of AgNPs. It was found that the coating of AgNPs reduced their toxicity and increased their stability. The therapeutic applications of AgNPs depend on their size, shape, and surface coatings. There are many functions of a coating substance, such as increasing stability, controlling the release of the core material or adding a specific function. The recent coating methods of AgNPs were presented in this article, such as polymerization, sol-gel and SILAR methods. The two main classes of coating materials (organic and inorganic) were also reviewed briefly. It was affirmed that the cytotoxicity of uncoated AgNPs is higher than that of coated AgNPs. The surface coating with different substances usually prevents the release of the ionic form of silver and change in the shape and size of AgNPs. The optical properties of AgNPs are greatly affected by the type of the coating material and thickness due to the shifts in the surface plasmon resonance of AgNPs even in the case of a thin layer form. The great affinity of AgNPs to biological substances such as proteins facilitates the production of biosensors with a high detection limit in comparison with the classical methods used in biological applications.

Although the researchers aim to find a simple, fast and inexpensive way to produce novel coated AgNPs with special physicochemical properties (decreasing the cytotoxicity or increasing the optical properties), they need to assess the safety of new nanoparticle materials on the living system and the environment. Finally, in the future, there is the requirement to understand the nature of the interaction mechanism between nanoparticles and the surrounding more clearly.

\section{Conflicts of interest}

The authors declare that there is no conflict of interest.

\section{Acknowledgements}

Cairo University as well as CMRDI are more appreciated by the authors for giving the facilities to pursue the current work.

\section{References}

1 C. A. Dos Santos, M. M. Seckler, A. P. Ingle, I. Gupta, S. Galdiero, M. Galdiero, A. Gade and M. Rai, J. Pharm. Sci., 2014, 103, 1931-1944.

2 F. D. Guerra, M. L. Campbell, D. C. Whitehead and F. Alexis, ChemistrySelect, 2017a, 2, 9889-9894.

3 F. D. Guerra, G. D. Smith, F. Alexis and D. C. Whitehead, Aerosol Air Qual. Res., 2017b, 17, 209-217.

4 S. Zhang, F. Ren, W. Wu, J. Zhou, L. Sun, X. Xiao and C. Jiang, J. Colloid Interface Sci., 2014, 427, 29-34.

5 C. M. Alexander and J. Goodisman, J. Colloid Interface Sci., 2014, 418, 103-112.
6 D. Wang, J. Ye, S. D. Hudson, K. C. K. Scott and S. LinGibson, J. Colloid Interface Sci., 2014, 417, 244-249.

7 A. Gebregeorgis, C. Bhan, O. Wilson and D. Raghavan, J. Colloid Interface Sci., 2013, 389, 31-41.

8 S. Cameron, F. Hosseinian and W. Willmore, Int. J. Mol. Sci., 2018, 19, 2030.

9 M. B. Gawande, A. Goswami, T. Asefa, H. Guo, A. V. Biradar, D.-L. Peng, R. Zboril and R. S. Varma, Chem. Soc. Rev., 2015, 44, 7540-7590.

10 M. M. S. Sanad, A. E. Shalan, M. M. Rashad and M. H. H. Mahmoud, Appl. Surf. Sci., 2015, 359, 315-322.

11 S. B. N. Krishna, P. Govender and J. K. Adam, Med. Technol. $S A, 2016,29,13-19$.

12 A. Travan, C. Pelillo, I. Donati, E. Marsich, M. Benincasa, T. Scarpa, S. Semeraro, G. Turco, R. Gennaro and S. Paoletti, Biomacromolecules, 2009, 10, 1429-1435.

13 K. Kang, D.-H. Lim, I.-H. Choi, T. Kang, K. Lee, E.-Y. Moon, Y. Yang, M.-S. Lee and J.-S. Lim, Toxicol. Lett., 2011, 205, 227234.

14 S. C. Boca, M. Potara, A.-M. Gabudean, A. Juhem, P. L. Baldeck and S. Astilean, Cancer Lett., 2011, 311, 131140.

15 D. Guo, L. Zhu, Z. Huang, H. Zhou, Y. Ge, W. Ma, J. Wu, X. Zhang, X. Zhou, Y. Zhang, Y. Zhao and N. Gu, Biomaterials, 2013, 34, 7884-7894.

16 H. Choi, J.-P. Lee, S.-J. Ko, J.-W. Jung, H. Park, S. Yoo, O. Park, J.-R. Jeong, S. Park and J. Y. Kim, Nano Lett., 2013, 13, 2204-2208.

17 A. Emamifar, M. Kadivar, M. Shahedi and S. SoleimanianZad, Innovative Food Sci. Emerging Technol., 2010, 11, 742748.

18 S. Kelesstemur, E. Kilic, Ü. Uslu, A. Cumbul, M. Ugur, S. Akman and M. Culha, Nano Biomed. Eng., 2012, 4, 170.

19 T. Endo, A. Shibata, Y. Yanagida, Y. Higo and T. Hatsuzawa, Mater. Lett., 2010, 64, 2105-2108.

20 S. Ahmed, M. Ahmad, B. L. Swami and S. Ikram, J. Radiat. Res. Appl. Sci., 2016, 9, 1-7.

21 B. Sadeghi and F. Gholamhoseinpoor, Spectrochim. Acta, Part A, 2015, 134, 310-315.

22 C. Levard, E. M. Hotze, B. P. Colman, A. L. Dale, L. Truong, X. Y. Yang, A. J. Bone, G. E. Brown, R. L. Tanguay, R. T. Di Giulio, E. S. Bernhardt, J. N. Meyer, M. R. Wiesner and G. V. Lowry, Environ. Sci. Technol., 2013, 47, 13440-13448.

23 Z. Luo, K. Zheng and J. Xie, Chem. Commun., 2014, 50, 51435155.

24 G. Dacarro, L. Cucca, P. Grisoli, P. Pallavicini, M. Patrini and A. Taglietti, Dalton Trans., 2012, 41, 2456.

25 P. Pallavicini, A. Taglietti, G. Dacarro, Y. Antonio DiazFernandez, M. Galli, P. Grisoli, M. Patrini, G. Santucci De Magistris and R. Zanoni, J. Colloid Interface Sci., 2010, 350, 110-116.

26 P. Pallavicini, G. Dacarro, M. Galli and M. Patrini, J. Colloid Interface Sci., 2009, 332, 432-438.

27 D. Wan, S. Yuan, K. G. Neoh and E. T. Kang, ACS Appl. Mater. Interfaces, 2010, 2, 1653-1662.

28 Z. Li, D. Lee, X. Sheng, R. E. Cohen and M. F. Rubner, Langmuir, 2006, 22, 9820-9823. 
29 P. J. Rivero, A. Urrutia, J. Goicoechea, C. R. Zamarreño, F. J. Arregui and I. R. Matías, Nanoscale Res. Lett., 2011, 6, 305.

30 A. J. Nolte, M. F. Rubner and R. E. Cohen, Langmuir, 2004, 20, 3304-3310.

31 T. C. Wang, R. E. Cohen and M. F. Rubner, Adv. Mater., 2002, 14, 1534-1537.

32 H. S. Yoo, T. G. Kim and T. G. Park, Adv. Drug Delivery Rev., 2009, 61, 1033-1042.

33 (a) A. Travan, E. Marsich, I. Donati, M. Benincasa, M. Giazzon, L. Felisari and S. Paoletti, Acta Biomater., 2011, 7, 337-346; (b) W. G. McMillan and E. Teller, J. Chem. Phys., 1954, 19, 25; (c) F. MacRitchie, Adv. Protein Chem., 1978, 32, 283.

34 (a) K. Vasilev, V. R. Sah, R. V. Goreham, C. Ndi, R. D. Short and H. J. Griesser, Nanotechnology, 2010, 21, 215102; (b) S. Agnihotri, S. Mukherji and S. Mukherji, RSC Adv., 2014, 4, 3974-3983; (c) C. Levard, B. C. Reinsch, F. M. Michel, C. Oumahi, G. V. Lowry and G. E. J. Brown, Environ. Sci. Technol., 2011, 45, 5260-5266.

35 M. C. Coll Ferrer, N. J. Hickok, D. M. Eckmann and R. J. Composto, Soft Matter, 2012, 8, 2423.

36 W. Yuan, Z. Lu, H. Wang and C. M. Li, Adv. Funct. Mater., 2012, 22, 1932-1939.

37 P. Lavalle, J.-C. Voegel, D. Vautier, B. Senger, P. Schaaf and V. Ball, Adv. Mater., 2011, 23, 1191-1221.

38 S. Joly, R. Kane, L. Radzilowski, T. Wang, A. Wu, R. E. Cohen, E. L. Thomas and M. F. Rubner, Langmuir, 2000, 16, 13541359.

39 (a) D. Lee, R. E. Cohen and M. F. Rubner, Langmuir, 2005, 21, 9651-9659; (b) D. Ficai and A. M. Grumezescu, in Micro and Nano Technologies, Nanostructures for Novel Therapy, Elsevier, 2017, pp. xxi-xxvi, ISBN 9780323461429, DOI: 10.1016/B9780-323-46142-9.00034-7.

40 (a) M. Behpour, J. Nanostruct., 2012, 2, 227-234; (b) E. Roy, S. Patra, S. Saha, R. Madhuri and P. K. Sharma, RSC Adv., 2015, 5, 95433-95442.

41 R.-S. Huang, B.-F. Hou, H.-T. Li, X.-C. Fu and C.-G. Xie, RSC $A d v ., 2015$, 5, 61184.

42 A. E. Shalan, M. Rasly, I. Osama, M. M. Rashad and I. A. Ibrahim, Ceram. Int., 2014, 40, 11619-11626.

43 M. Rasly, M. Afifi, A. E. Shalan and M. M. Rashad, Appl. Phys. A: Mater. Sci. Process., 2017, 123, 331.

44 C. Radheshkumar and H. Münstedt, React. Funct. Polym., 2006, 66, 780-788.

45 R. Ghosh Chaudhuri and S. Paria, Chem. Rev., 2012, 112, 2373-2433.

46 W. Feng, Z. Fang, J. Yang, B. Zheng and Y. Jiang, Carbohydr. Res., 2011, 346, 352-356.

47 R. Asapu, N. Claes, S. Bals, S. Denys, C. Detavernier, S. Lenaerts and S. W. Verbruggen, Appl. Catal., B, 2017, 200, 31-38.

48 L. Kvítek, A. Panáček, J. Soukupová, M. Kolář, R. Večeřová, R. Prucek, M. Holecová and R. Zbořil, J. Phys. Chem. C, 2008, 112, 5825-5834.

49 O. Tzhayik, P. Sawant, S. Efrima, E. Kovalev and J. T. Klug, Langmuir, 2002, 18, 3364-3369.
50 X. Z. Lin, X. Teng and H. Yang, Langmuir, 2003, 19, 1008110085.

51 Y. Lu, G. L. Liu and L. P. Lee, Nano Lett., 2005, 5, 5-9.

52 B. J. Wiley, Y. Chen, J. McLellan, Y. Xiong, Z.-Y. Li, D. Ginger and Y. Xia, Nano Lett., 2007, 7, 1032-1036.

53 M. Yamamoto and M. J. Nakamoto, Mater. Chem., 2003, 13, 2064.

54 E. Jimenez-Villar, V. Mestre, P. C. de Oliveira and G. F. de Sá, Nanoscale, 2013, 5, 12512.

55 E. Jimenez-Villar, V. Mestre, P. C. De Oliveira, W. M. Faustino, D. S. Silva and G. F. De Sá, Appl. Phys. Lett., 2014, 104, 2-7.

56 V. V. Hardikar and E. Matijević, J. Colloid Interface Sci., 2000, 221, 133-136.

57 V. A. Ermakov, E. Jimenez-Villar, J. M. C. Da Silva Filho, E. Yassitepe, N. V. V. Mogili, F. Iikawa, G. F. De Sá, C. L. Cesar and F. C. Marques, Langmuir, 2017, 33, 22572262.

58 L. Carlini, H. Chibli, X. Zhang and J. Nadeau, Rev. Nanosci. Nanotechnol., 2013, 2, 42-62.

59 S. V. Nalage, S. V. Bhosale, S. V. Bhosale and R. S. Bhosale, J. Colloid Sci. Biotechnol., 2013, 2, 195-199.

60 B. W. Boote, H. Byun and J.-H. Kim, J. Nanosci. Nanotechnol., 2014, 14, 1563-1577.

61 P. Boomi, H. G. Prabu and J. Mathiyarasu, Colloids Surf., B, 2013, 103, 9-14.

62 B. Karthikeyan and M. Murugavelu, Sens. Actuators, B, 2012, 163, 216-223.

63 S. Yu, Q. Lou, K. Han, Z. Wang and H. Zhu, Int. J. Hydrogen Energy, 2012, 37, 13365-13370.

64 M. Schaal, A. Pickerell, C. Williams and J. Monnier, J. Catal., 2008, 254, 131-143.

65 A. E. Shalan and M. M. Rashad, Appl. Surf. Sci., 2013, 283, 975-981.

66 M. M. Rashad and A. E. Shalan, J. Mater. Sci.: Mater. Electron., 2013, 24, 3189-3194.

67 P. Roy and S. K. Srivastava, CrystEngComm, 2015, 17, 78017815.

68 W. Alshammari, D. S. Patil, S. A. Pawar and J. C. Shin, Mater. Today Chem., 2017, 5, 72-80.

69 R. de Lima, A. B. Seabra and N. Durán, J. Appl. Toxicol., 2012, 32, 867-879.

70 P. Dallas, V. K. Sharma and R. Zboril, Adv. Colloid Interface Sci., 2011, 166, 119-135.

71 Y. Teow, P. V. Asharani, M. P. Hande and S. Valiyaveettil, Chem. Commun., 2011, 47, 7025.

72 K. Soto, K. Garza and L. Murr, Acta Biomater., 2007, 3, 351358.

73 T. H. Kim, M. Kim, H. S. Park, U. S. Shin, M. S. Gong and H. W. Kim, J. Biomed. Mater. Res., Part A, 2012, 100, 10331043.

74 X. Yang, A. P. Gondikas, S. M. Marinakos, M. Auffan, J. Liu, H. Hsu-Kim and J. N. Meyer, Sci. Technol., 2012, 46, 11191127.

75 M. Akter, M. T. Sikder, M. M. Rahman, A. K. M. A. Ullah, K. F. B. Hossain, S. Banik, T. Hosokawa, T. Saito and M. Kurasaki, J. Adv. Res., 2017, 9, 1-16. 
76 A. K. Suresh, D. A. Pelletier, W. Wang, J. L. Morrell-Falvey, B. Gu and M. J. Doktycz, Langmuir, 2012, 28, 2727-2735.

77 K. A. Dawson, S. Anguissola and I. Lynch, Nanotoxicology, 2012, 7, 346-349.

78 P. Cvjetko, A. Milošić, A.-M. Domijan, I. V. Vrček, S. Tolić, P. P. Štefanić, I. Letofsky-Papst, M. Tkalec and B. Balen, Ecotoxicol. Environ. Saf., 2017, 137, 18-28.

79 (a) B. Das, M. I. Khan, R. Jayabalan, S. K. Behera, S. Il Yun, S. K. Tripathy and A. Mishra, Sci. Rep., 2016, 6, 1-12; (b) R. Foulkes, M. A. Asgari, A. Curtis and C. Hoskins, ACS Appl. Nano Mater., 2019, 2(4), 1758-1772; (c) D. C. Tang, A. F. Gazdar and D. P. Carbone, J. Immunol. Methods, 1996, 189, 173-182.

80 K. C. Nguyen, V. L. Seligy, A. Massarsky, T. W. Moon, P. Rippstein, J. Tan and A. F. Tayabali, J. Phys.: Conf. Ser., 2013, 429, 012025.

81 L. Böhmert, B. Niemann, A. F. Thünemann and A. Lampen, Arch. Toxicol., 2012, 86, 1107-1115.

82 M. Ahamed, M. Karns, M. Goodson, J. Rowe, S. M. Hussain, J. J. Schlager and Y. Hong, Toxicol. Appl. Pharmacol., 2008, 233, 404-410.

83 V. Bastos, J. M. P. Ferreira-de-Oliveira, J. Carrola, A. L. Daniel-da-Silva, I. F. Duarte, C. Santos and H. Oliveira, J. Environ. Sci., 2017, 51, 191-201.
84 A. Amirjani, M. Bagheri, M. Heydari and S. Hesaraki, Sens. Actuators, B, 2016, 227, 373-382.

85 K. L. Kelly, E. Coronado, L. L. Zhao and G. C. Schatz, J. Phys. Chem. B, 2003, 107, 668-677.

86 A. P. Alivisatos, K. P. Johnsson, X. Peng, T. E. Wilson, C. J. Loweth, M. P. Bruchez and P. G. Schultz, Nature, 1996, 382, 609-611.

87 B. R. Martin, D. J. Dermody, B. D. Reiss, M. Fang, L. A. Lyon, M. J. Natan and T. E. Mallouk, Adv. Mater., 1999, 11, 10211025.

88 Y. Cao, R. Jin and C. A. Mirkin, J. Am. Chem. Soc., 2001, 123, 7961-7962.

89 L. Xu, G. Zheng, Y. Liu, J. Su, W. Kuang and W. Rao, Optik, 2017, 147, 6-13.

$90 \mathrm{H}$. K. Koduru, L. Marino, V. Janardhanam and N. Scaramuzza, Surf. Interfaces, 2016, 5, 47-54.

91 C. Li, M. Liu, L. Yan, N. Liu, D. Li, J. Liu and X. Wang, J. Lumin., 2017, 190, 1-5.

92 B. Ajitha, Y. A. K. Reddy, P. S. Reddy, H.-J. Jeon and C. W. Ahn, RSC Adv., 2016, 6, 36171-36179.

93 S. Davidović, V. Lazić, I. Vukoje, J. Papan, S. P. Anhrenkiel, S. Dimitrijević and J. M. Nedeljković, Colloids Surf., B, 2017, 160, 184-191.

94 J. C. Heckel, Synthesis and optical properties of silver nanostructures, Clemson University, Huang, 2010. 